\title{
Organic Solvent Effects in Biomass Conversion Reactions
}

Li Shuai and Jeremy Luterbacher*a]

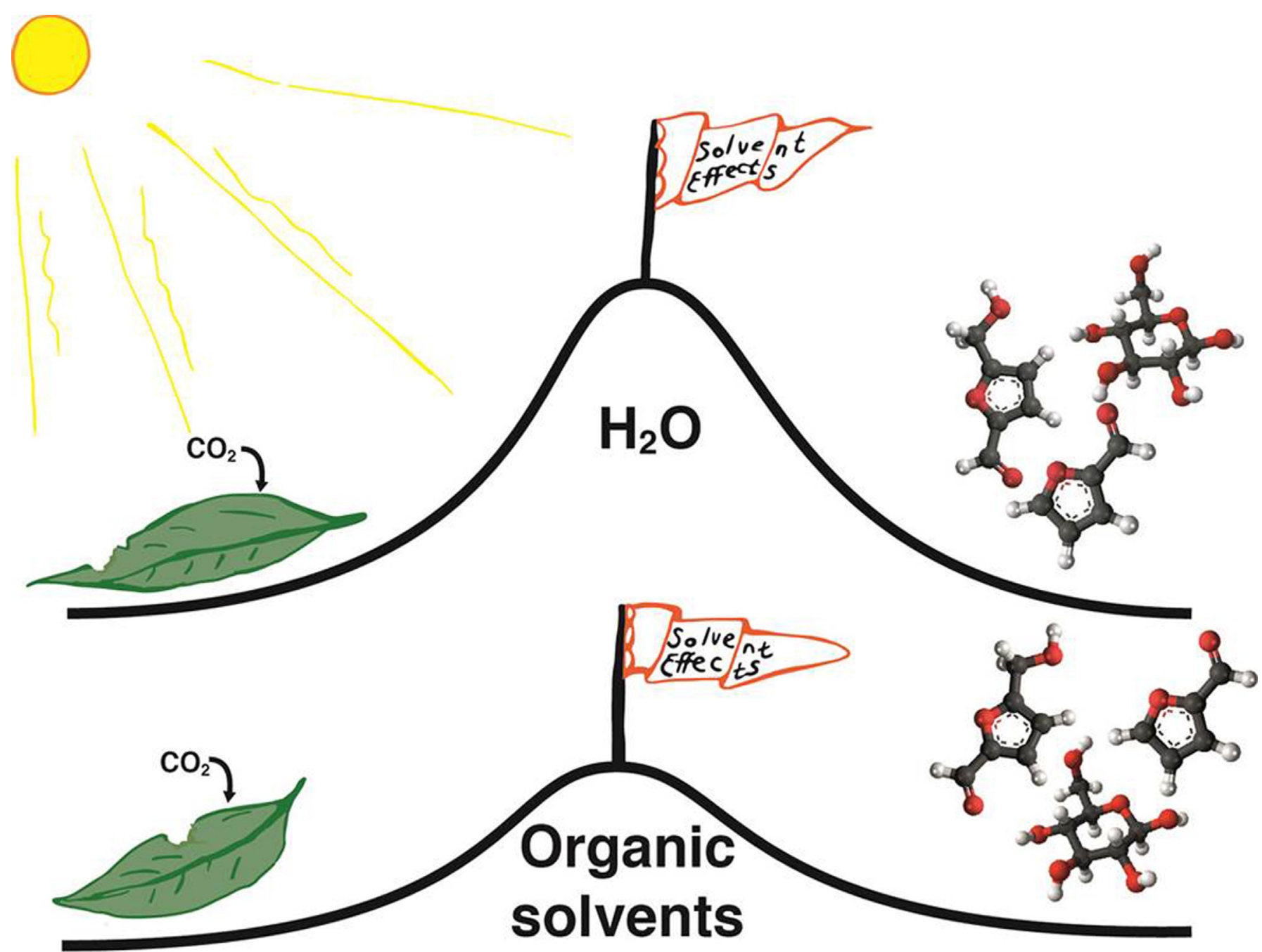


Transforming lignocellulosic biomass into fuels and chemicals has been intensely studied in recent years. A large amount of work has been dedicated to finding suitable solvent systems, which can improve the transformation of biomass into valueadded chemicals. These efforts have been undertaken based on numerous research results that have shown that organic solvents can improve both conversion and selectivity of biomass to platform molecules. We present an overview of these organic solvent effects, which are harnessed in biomass conversion processes, including conversion of biomass to sugars, conversion of sugars to furanic compounds, and production of lignin monomers. A special emphasis is placed on comparing the solvent effects on conversion and product selectivity in water with those in organic solvents while discussing the ori- gins of the differences that arise. We have categorized results as benefiting from two major types of effects: solvent effects on solubility of biomass components including cellulose and lignin and solvent effects on chemical thermodynamics including those affecting reactants, intermediates, products, and/or catalysts. Finally, the challenges of using organic solvents in industrial processes are discussed from the perspective of solvent cost, solvent stability, and solvent safety. We suggest that a holistic view of solvent effects, the mechanistic elucidation of these effects, and the careful consideration of the challenges associated with solvent use could assist researchers in choosing and designing improved solvent systems for targeted biomass conversion processes.

\section{Introduction}

Because of its potential as a renewable carbon source, lignocellulosic biomass has been the subject of increasing interest from academia, industry, and government. Although many biomass conversion technologies were invented in the last few decades, few profitable processes are currently in operation. ${ }^{[1]}$ This is partly due to the fact that for some low-value products from biomass a very small to inexistent profit margin exists. Furthermore, for higher-value products, biomass conversion processes often suffer from low or slow conversion and/or low selectivity. In cases were conversion and selectivity are high, costly catalysts (e.g., enzymes and noble metals), costly organic solvents, high energy inputs, high infrastructure costs, and multiple refining steps are often required to obtain the desired products. $^{[1]}$

To make biorefineries viable, selective conversion of biomass into selected high-value fuels and chemicals must be improved while keeping the process economical. Increasing conversion (and the selectivity of the reaction) of biomass to key platform molecules such as sugars and furanic compounds (i.e., furfural and 5-hydroxymethylfurfural) is seen as especially important. ${ }^{[2]}$ A number of studies have indicated that it is difficult to improve the selective conversion of biomass to sugars, furfural, and/or 5-hydroxymethylfurfural (HMF) in aqueous solutions without significantly increasing catalyst loadings or using hightemperature $\left(>220^{\circ} \mathrm{C}\right)$ processes. ${ }^{[3]}$ High catalyst loadings (e.g., acid and base) require catalyst recycling, neutralization, and/or disposal whereas high temperature processes increase energy consumption and require impractically short residence times $(<10 \mathrm{~s})$. Therefore, even though water is an attractive choice owing to its low cost, low toxicity, and environmental friendli-

\footnotetext{
[a] Dr. L. Shuai, Prof. J. Luterbacher

Laboratory of Sustainable and Catalytic Processing

Institute of Chemical Sciences and Engineering

École polytechnique fédérale de Lausanne (EPFL)

Station 6, CH.H2.545, 1015 Lausanne (Switzerland)

E-mail: jeremy.luterbacher@epfl.ch

iD $\mathrm{ORCID(s)}$ from the author(s) for this article is/are available on the WWW under http://dx.doi.org/10.1002/cssc.201501148.
}

ness, numerous studies have explored the use of organic solvents, which can significantly improve the selective conversion of biomass into sugars and furanic compounds. ${ }^{[4-8]}$ These research results indicate that, in certain cases, the effects of using specific organic solvents can have a greater influence on reaction rates and product selectivities than changing catalysts and/or optimizing reaction temperatures. For example, recent results have shown that the use of organic solvents [including ionic liquids (ILs), which always contain at least one organic ion] can lead to HMF yields from glucose that are 2-3 times higher than in the aqueous phase. ${ }^{[9-14]}$ Similarly, the use of organic solvents during non-enzymatic saccharification processes have led to similar increases in sugar yields ${ }^{[15]}$ and, in the case of ILs, enabled saccharification of cellulose at temperatures where no reaction would occur in pure water. ${ }^{[16]}$

Methods and/or routes for converting biomass into sugars, HMF, levulinic acid, hydrocarbon fuels, and lignin derivatives were the focus of recent reviews. ${ }^{[1,3,17-21]}$ Reviews on specific reaction media such as ILs or $\mathrm{CO}_{2}$ used in biomass conversion were also published. ${ }^{[22]}$ However, these reviews focused on specific reactions or products, and/or on reporting specific product yields and concentrations. In contrast, the objective of this Review is to provide an overview and comparison of the use of organic solvents in biomass conversion and especially of their effects. We focus specifically on those solvent effects that drive several important reactions in the production of biomass-derived molecules, including sugars, furans, and lignin monomers. First, we briefly summarize biomass conversion processes that benefited from organic solvent use compared to aqueous systems (Section 2). We begin our discussion on solvent effects by discussing their general definitions (Section 3). We then discuss solvent effects that are largely due to changing the solubility of reactants or products (Section 4) and then discuss those that affect reaction kinetics in more detail (Section 5). In spite of the considerable advantages of organic solvents in biomass conversion, their use in industry, especially in the production of low-value biorefinery molecules, could face several challenges. These challenges are discussed in the last part of our Review (Section 6). We propose that a careful review of these themes can shed light on the choice and 
future design of solvent systems for a given biomass conversion process.

\section{Brief Summary of Biomass Conversion Pro- cesses}

Lignocellulosic biomass, which is the most abundant form of terrestrial biomass, is typically composed of $40-50 \%$ cellulose, $10-30 \%$ hemicellulose, $10-30 \%$ lignin, $1-10 \%$ extractives, and up to $20 \%$ ash. ${ }^{[23]}$ Cellulose, hemicellulose, and lignin typically account for $80-90 \%$ of the biomass's weight; thus, their components dictate the principal platform molecules that can be obtained from biomass. These platform molecules consist mainly of the monomers of these three constitutive polymers or their direct dehydration or hydrogenation products (Figure 1). These products can be further processed into other value-added chemicals and fuels through biological and/or chemical routes. ${ }^{[3,20,24]}$ The cost-effective production of these primary chemicals from lignocellulosic biomass is still one of the most important barriers limiting the development of the whole biorefinery industry. ${ }^{[3,24]}$

In the field of biomass conversion, the oldest and most wellknown solvent effect is the significant enhancement of lignin removal during acidic organosolv pretreatment compared to

\begin{abstract}
Dr. Li Shuai obtained his Ph.D. from the University of Wisconsin-Madison in 2012. He was a group leader in the R\&D center of Vland Biotech Group in China for two years prior to moving to EPFL a postdoctoral scientist in 2015. $\mathrm{He}$ is the (co)author of six patents and eleven peer-reviewed journal articles. His research focuses on developing innovative pathways for conversion of biomass to value-added fuels, chemicals and materials. Currently he is working on catalytic depolymerization of lignin into monomers.
\end{abstract}

Prof. Jeremy Luterbacher received B.Sc. and M.Sc. degrees in Chemical Engineering from EPFL, with a research stay at the Massachusetts Institute of Technology (MIT) in 2007. He then moved to Cornell University to pursue doctoral studies in the research groups of Prof. Larry Walker and Prof. Jeff Tester. At Cornell, Prof. Luterbacher was awarded the Austin Hooey Graduate Research Excellence Recognition Award for his PhD work. He then joined the Great Lakes Bioenergy Research Center and the University of Wisconsin-Madison as a Swiss NSF Postdoctoral Scholar under the supervision of Prof. Jim Dumesic. Prof. Luterbacher returned to EPFL in 2014 as a tenure-track Assistant Professor and head of the Laboratory for Sustainable and Catalytic Processing. dilute acid pretreatment. At a similar loading of acid, over $70 \%$ of lignin can be removed in organic solvents compared to $20 \%$ lignin removal in aqueous phase (Table 1). The rates of enzymatic sugar production from the remaining cellulose and the yields of sugars were shown to be significantly increased due to lignin removal. ${ }^{[32]}$ Since this early work, many other processes have used organic solvents to enhance yields. Table 2 summarizes these processes and compares results obtained with organic solvents to comparable aqueous systems. Because of the strong dependence of yields on reactant concentration, we only included work that was performed at relatively high feed concentrations ( $>5 \mathrm{wt} \%$ ) to ensure a meaningful comparison. Similar to organosolv pretreatment, pretreatment with ILs, consisting of an organic cation and an inorganic or organic anion, has been shown to lead to high glucose yields after enzymatic hydrolysis even at pretreatment temperatures below $100^{\circ} \mathrm{C}^{[21]}$ Due to solvent effects that are discussed more in detail below, organic solvents such as ILs can disrupt cellulose crystallinity, which drastically increases the cellulose hydrolysis rates and yields. ${ }^{[54,55]}$ In direct saccharification processes (where no enzymes are used), dilute-acid treatments were usually conducted at high temperatures $\left(>240^{\circ} \mathrm{C}\right)$ to break the crystalline structure. These temperatures led to the increased degradation of sugars, thereby lowering yields to values between 50 and $60 \% .{ }^{[125]}$ Yields around $80 \%$ were obtained using flow-through processes, but these led to final sugar concentrations below $1 \mathrm{wt} \%{ }^{[3]}$ Concentrated acid saccharification processes result in glucose yields near $100 \%$ at temperatures below $100^{\circ} \mathrm{C}$, but require extensive acid recovery operations to be economical and suffer from high corrosiveness. ${ }^{[126]}$ Similar to their effect during pretreatment, ILs can enable saccharification at temperatures below $150^{\circ} \mathrm{C}$ owing to their ability to disrupt cellulose crystallinity. ${ }^{[16]}$ At these temperatures, virtually no saccharification occurs in aqueous systems. Organic solvents such as $\gamma$-valerolactone (GVL) have been shown to enhance saccharification rates by dissolving lignin and increasing the activity of acidic protons. ${ }^{[5,15]} \mathrm{GVL}$-water systems were shown to enhance glucose yields during acidcatalyzed saccharification to near $80 \%$, which was twice as much as the yield obtained with the identical system using water. $^{[15]}$ The lignin dissolving ability of organic solvents was also used to facilitate the depolymerization of lignin especially because of the resulting increased mass transfer between the catalyst and solubilized substrate. Hydrogenolysis of lignin in dioxane, GVL, or methanol has led to yields near $50 \%$, which are the highest observed for this type of reaction. ${ }^{[79,87,127]}$

For furanic compound production, organic solvents significantly affected the thermodynamics of reactants, catalysts, and products, thus significantly affecting the outcomes of sugar dehydration reactions. ${ }^{[128-131]}$ Direct comparison of organic and aqueous solvent systems showed that typical HMF yields from glucose or fructose could reach values that were nearly twice as high in the organic system (Table 2). Similarly, attainable furfural yields were typically $30 \%$ higher in organic solvents compared to water.

Biomass liquefaction reactions typically involve the liquidphase deconstruction of biomass to small organic oxygenates 


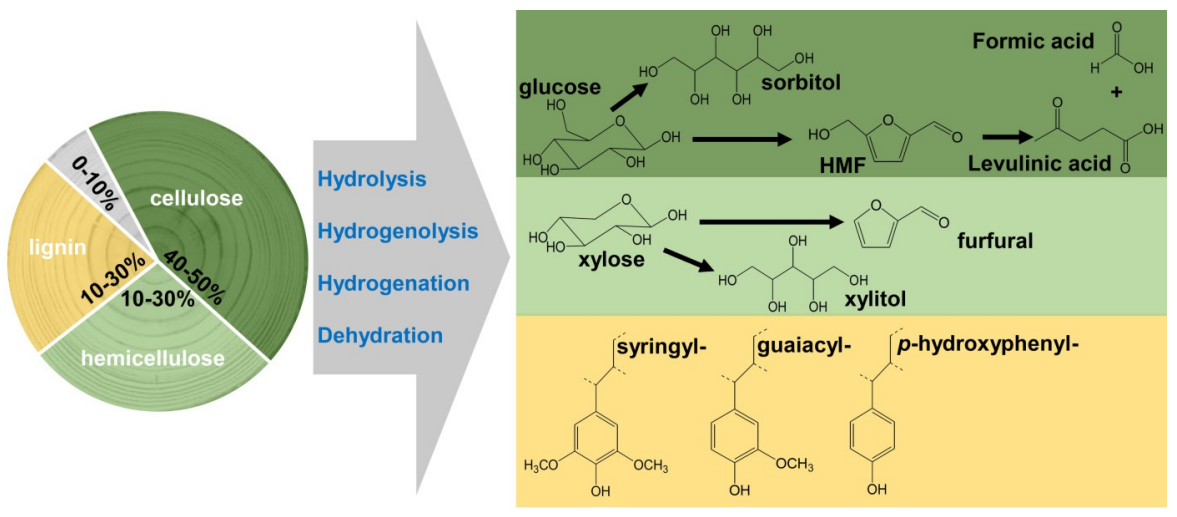

Figure 1. Major platform chemicals produced directly from lignocellulosic biomass. Only the products that have been produced at a yield $>5$ wt $\%$ of real lignocellulosic biomass in one single step are shown. Adapted from Luterbacher et al..$^{[3]}$

\begin{tabular}{|c|c|c|c|}
\hline $\begin{array}{l}\text { Pretreatment } \\
\text { method }\end{array}$ & Reaction conditions & $\begin{array}{l}\text { Lignin re- } \\
\text { movall }^{[a]}\end{array}$ & Ref. \\
\hline dilute acid & $\begin{array}{l}\text { water } \\
<1 \% \text { acid } \\
160-200^{\circ} \mathrm{C}\end{array}$ & $<20 \%$ & {$[25-31]$} \\
\hline methanol & $\begin{array}{l}60-80 \% \text { aqueous methanol } \\
\text { solution } \\
<1 \% \text { acid } \\
160-170^{\circ} \mathrm{C}\end{array}$ & $>70 \%$ & {$[32-36]$} \\
\hline ethanol & $\begin{array}{l}40-60 \% \text { aqueous ethanol so- } \\
\text { lution } \\
<1 \% \text { acid } \\
160-190^{\circ} \mathrm{C}\end{array}$ & $>70 \%$ & {$[37-42]$} \\
\hline acetone & $\begin{array}{l}50-70 \% \text { aqueous acetone } \\
\text { solution } \\
0.05-0.25 \% \text { acid } \\
180-220^{\circ} \mathrm{C}\end{array}$ & $>90 \%$ & {$[32,43,44]$} \\
\hline acetic acid & $\begin{array}{l}50-70 \% \text { aqueous acetic acid } \\
\text { solution } \\
0.05-0.25 \% \text { acid } \\
180-220^{\circ} \mathrm{C}\end{array}$ & $>80 \%$ & {$[45-50]$} \\
\hline THF & $\begin{array}{l}50 \% \text { aqueous THF solution } \\
0.5 \% \text { acid } \\
150{ }^{\circ} \mathrm{C}\end{array}$ & $>75 \%$ & [51] \\
\hline GVL & $\begin{array}{l}80-90 \% \text { aqueous GVL solu- } \\
\text { tion } \\
0.5 \% \text { acid } \\
120-220^{\circ} \mathrm{C}\end{array}$ & $>80 \%$ & [15] \\
\hline IL & $\begin{array}{l}<10 \% \text { water content } \\
50-130^{\circ} \mathrm{C}\end{array}$ & $>80 \%$ & {$[52-55]$} \\
\hline
\end{tabular}

at temperatures between 200 and $380^{\circ} \mathrm{C} .{ }^{[131]}$ In these processes, organic solvents can be used to improve and accelerate lignin dissolution and to affect cellulose crystallinity, thus decreasing the amount of solid residues formed. ${ }^{[115]}$ Several processes developed by Shell showed that the use of organic solvents, including biomass-derived GVL and guaiacol, lead to enhanced yields of liquid and gaseous products, in some cases up to $100 \%$ (Table 2 ).
In summary, organic solvents play an increasingly important role in enhancing the yields of multiple processes. The reasons behind these yield increases are not completely understood. However, in recent years, the combination of improved computational chemistry methods and increasing amount of experimental data have allowed researchers to gain mechanistic insights into these solvent effects, which we discuss in the following sections.

\section{Definition of Solvent Effects}

In the previous section, we broadly discussed two types of biomass conversion processes: processes using aqueous solvent systems and processes using organic solvent systems. Organic solvents can be further categorized into four types: non-polar solvents (e.g., hexane and dimethyl ether), polar aprotic solvents (e.g., ketones, DMSO, DMF, THF, and GVL), polar protic solvents (e.g., methanol, ethanol, and acetic acid), and ILs. The definitions and properties of these four types of solvents are summarized in Table 3.

Solvent effects refer primarily to changes induced by the solvent in chemical reactivity including reaction rate, reaction pathways, product distributions, and yields. Changes in interactions between the solvent and solute that occur because of changes in hydrogen bonding and differing dipole moments can significantly alter the solubility and the thermodynamic state of reactants, transition states, activation energy, and products in a single reaction. ${ }^{[133]}$ Therefore, reaction rates and product selectivity can be controlled to a certain degree by simply changing the solvent medium.

The effect of solvents on chemical reactivity has been widely observed and has been explained in different ways, often using reactions that are less complex than those occurring during biomass conversion. Originally, solvent effects were explained based on viscosity and changes in the dielectric constant. ${ }^{[134,135]}$ More recently, with modern instrumental technologies, the use of spectroscopic instrument has generated several empirical parameters such as solvent polarizability, Lewis acidity, Lewis basicity, and dipolarity, to define solvent effects based on the solvating ability and polarity scale of the sol- 


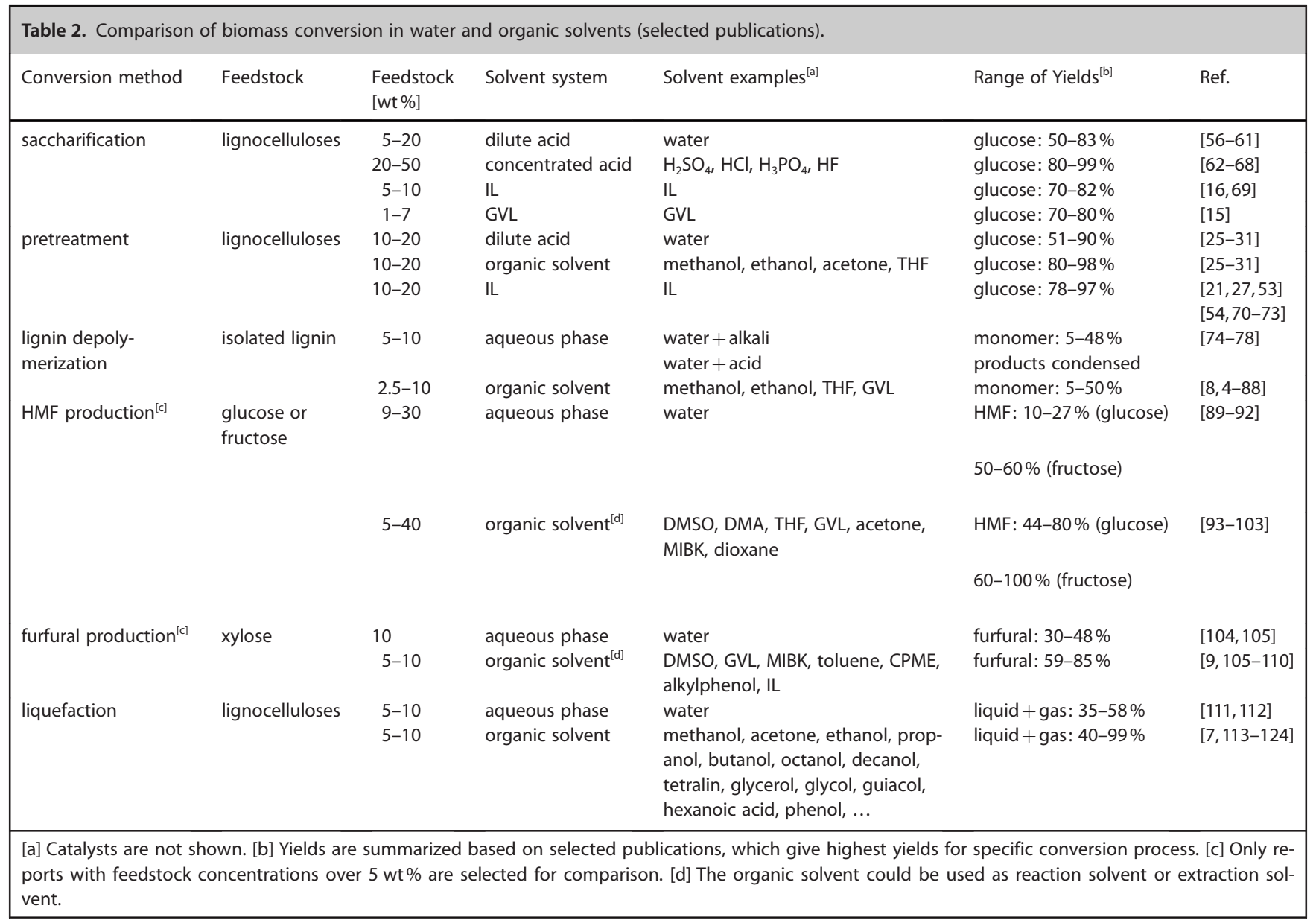

Table 3. Definitions and properties of various types of solvents.

\begin{tabular}{|c|c|c|c|}
\hline Solvent type & Definition & Properties & Examples \\
\hline non polar & molecules do not have an electric dipole or a multipole moment & $\begin{array}{l}\text { - solvent do not have or accept an acidic proton or } \\
\text { create hydrogen bonds } \\
\text { - not miscible with other polar solvent, chemical and } \\
\text { salts except nonpolar solvent, chemicals and poly- } \\
\text { meric materials }\end{array}$ & $\begin{array}{l}\text { hexane, di- } \\
\text { methyl ether }\end{array}$ \\
\hline polar protic & $\begin{array}{l}\text { molecules have an electric dipole or a multipole moment, have a hy- } \\
\text { drogen atom bound to an oxygen (a hydroxyl group) or a nitrogen } \\
\text { (an amine group) }\end{array}$ & $\begin{array}{l}\text { - solvents have lone electron pair and can accept hy- } \\
\text { drogen bonds } \\
\text { - solvents have an acidic proton and can donate hy- } \\
\text { drogen for hydrogen bonding }\end{array}$ & $\begin{array}{l}\text { water, etha- } \\
\text { nol, formic } \\
\text { acid }\end{array}$ \\
\hline aprotic & $\begin{array}{l}\text { molecules have an electric dipole or multipole moment, do not have } \\
\text { a hydrogen atom bound to an oxygen and nitrogen which are usually } \\
\text { double-bound to carbon atom }\end{array}$ & $\begin{array}{l}\text { - solvents have lone electron pair and can accept hy- } \\
\text { drogen bonds } \\
\text { - solvents do not have acidic hydrogen centers }\end{array}$ & $\begin{array}{l}\text { DMF, DMSO, } \\
\text { GVL }\end{array}$ \\
\hline IL & $\begin{array}{l}\text { a salt in which the ions are poorly coordinated, which results in these } \\
\text { solvents being liquid below } 100^{\circ} \mathrm{C} \text {, or even at room temperature. at } \\
\text { least one ion has a delocalized charge and one component is organic, } \\
\text { which prevents the formation of a stable crystal lattice }\end{array}$ & $\begin{array}{l}\text { - high viscosity, low vapor pressure, low combustibil- } \\
\text { ity, excellent thermal stability, } \\
\text { - solvents can solvate a range of polar and non-polar } \\
\text { compounds. }\end{array}$ & {$[\mathrm{EMIM}]^{+} \mathrm{Cl}^{-[\mathrm{a}]}$} \\
\hline
\end{tabular}

vent. ${ }^{[136]}$ Nowadays, with the development of computational methods, various theoretical models have successfully been used to validate this experimental data. ${ }^{[137-140]}$

Solute-solvent interactions considerably influence the structural and orientational parameters of the solute. From the sol- ute's structural standpoint, solvent effects can be categorized as static or dynamic solvation effects. Static effects refer to the stabilization of reactants, changes in transition state, and stabilization of products, that is, how the solvent affects the free energies of these species. ${ }^{[141]}$ Changing the free energy of the 
reactants or the transition state will especially affect the reaction's activation energy and modify the rate. If the reaction is largely controlled by static effects, the solvent's relaxation is fast compared to the activation process and the activated complex is largely in thermal equilibrium with the solvent. However, this equilibrium assumption is usually not valid for a chemical reaction in a strongly dipolar and/or slow-relaxing solvent. ${ }^{[141-148]}$ In this situation, rate constants will depend on solvent dynamics and will vary with parameters that include density, internal pressure, or viscosity. Especially for rapid chemical reactions, the slow relaxation of the solvent will affect the activation process. In such cases, the activation process can be limited by the time taken by molecules to reorient themselves around the transition state. Recent studies have shown that ILs can exhibit slow relaxation, which is attributed to their strong cation-anion interaction and high viscosity. ${ }^{[149,150]}$ In most cases, dynamic effects will slow down reaction rates, which are then generally assumed to be inversely related to the viscosity of the solvent. ${ }^{[148]}$

Solvent effects often cannot be simply explained by a single factor, but there is usually a dominant one that governs reactivity. Static [Eq. (1)] and dynamic [Eq. (2)] effect-dependent rate constant expressions can, therefore, usually be written as:

$k=A e^{-\frac{\Delta E}{R T}}$

$k=\frac{A}{f} e^{-\frac{\Delta E}{R T}}(f \propto \eta)$

where $k$ is the rate constant, $A$ is the pre-exponential factor, $\Delta E$ is the activation energy, $R$ is the ideal gas constant, $T$ is the absolute temperature, and $f$ is the fraction coefficient. It is usually assumed that $f$ is related linearly to the viscosity of the solvent, the rate becomes inversely proportional to the solvent's viscosity. ${ }^{[151]}$

Solvent effects have been widely observed in different areas of chemistry such as photochemistry, ${ }_{1}^{[146,152-154]}$ biochemistry, ${ }^{[147,155-159]}$ and catalysis. ${ }^{[160-163]}$ Of these studies most discuss static effects, which often play a greater role in most chemical reactions compared to dynamic effects. ${ }^{[147,164-166]}$ In addition, static effects are better understood and, therefore, tend to be discussed more often in the literature. This is especially true for biomass conversion where almost all studies relied on static phenomena to explain solvent effects in biomass conversion reactions. Furthermore, an additional characteristic of biomass conversion reactions is that they usually feature several insoluble fractions such as cellulose, hemicellulose, or lignin. The reduced solubility of these components, which limits their accessibility to the catalyst, is often a key factor controlling the reaction.

For this reason, in the following sections, we divided solvent effects into two categories, which better represent the literature on biomass conversion reactions: effects on the solubility of biomass components and their derivatives and effects on chemical thermodynamics. These two types of effects can be well represented by considering the typical kinetic expression of a first-order reaction rate [Eq. (3)]: $r=k \times C$

Where $r$ is the reaction rate, $C$ is the reactant concentration, and $k$ is the rate constant. Reaction rates in biomass conversion are often restricted by the low concentrations $(C)$ of the mostly insoluble biomass components in the solvent. Therefore, conversion can be significantly improved by increasing the biomass solubility. The other method of increasing rates is to change the rate constant $(k)$, which can be achieved by using a solvent that affects the thermodynamics of the molecules and complexes that participate in the chemical reaction.

\section{Solvent Effects on the Solubilities of Bio- mass Components and their Derivatives}

A solvent can generally dissolve solutes or mix with other solvents that have similar polarities. For example, water, a polar solvent, can dissolve glucose, a polar compound, but not the non-polar compound hexane. However, water cannot dissolve cellulose, the polymeric form of glucose, which has a similar polarity to glucose by virtue of their similar chemical structures. This illustrates that, in addition to polarity, several other solvent parameters are associated directly or indirectly with solubility, including: ${ }^{[167]}$

1. molecular size or volume,

2. molecular surface area,

3. polarizability, and

4. hydrogen bonding strength.

For solutes without solubility parameters, several empirical and semi-empirical models, ${ }^{[168]}$ including the Kamlet-Taft solubility parameters ${ }^{[169,170]}$ and Hansen solubility parameters, ${ }^{[171]}$ were developed to predict the solubility of a solute in a solvent. The two models attribute solubility to different factors. The Hansen model defines the parameter as related to the total cohesive energy, which is measured as the vaporization heat of a pure solvent. The total cohesive energy of a solvent is further divided into three different intermolecular interactions: hydrogen bonding, dispersion forces, and dipole forces. ${ }^{[171]}$ The advantage of the Hansen model is that the solubility parameter of an unknown solute and solvent system can be calculated from empirical data. ${ }^{[171]}$ Notably, the Hansen model has been widely used to screen solvents for dissolving lignin in biomass pretreatment. ${ }^{[8,172]}$ The Kamlet-Taft parameters attribute solubility to polarity, hydrogen bonding basicity, and hydrogen bonding acidity, which can be determined by measuring the UV/Vis spectra of specific dyes in the solvent of interest. ${ }^{[169,173]}$ Kamlet-Taft has also been used to predict the solubility of biomass in ILs. The cations and anions of ILs have both acidic and basic effects during the dissolution of biomass, which makes Kamlet-Taft a good model for predicting the behavior of these systems. ${ }^{[170]}$ Brandt et al. recently reviewed the solubility of biomass in ILs and discussed these solubility parameters in more detail. ${ }^{[173]}$

According to these parameters, several possible strategies to increase solubility are: (1) decrease the molecular size or volume to improve the solvation of the solute; (2) adjust sol- 
vent polarity to bring it closer to the solute's polarity, and (3) increase the hydrogen bonding strength between the solute and solvent to improve interpenetration between the two sets of molecules.

Within lignocellulosic biomass, cellulose fibers that are typically covered by amorphous hemicellulose, is further bound together by lignin to form the plant cell wall. ${ }^{[23]}$ The dissolution and depolymerization of cellulose imbedded within lignocellulosic biomass is more complicated than the dissolution of pure cellulose due to the presence of these two other components. At least part of lignin and hemicellulose need to be removed to improve the accessibility of cellulose to homogeneous catalysts. Cellulose accessibility has been shown to be an important issue controlling the rates and extent of deconstruction in both enzyme-- ${ }^{[174-176]}$ and acid-catalyzed ${ }^{[177,178]}$ hydrolysis. Additionally, the crystal structure of cellulose is another major barrier preventing the deconstruction of cellulose, especially at moderate temperature and even in the case of pure cellulose. ${ }^{[23]}$ In crystalline cellulose, strong hydrogen bonds among cellulose hydroxyl groups significantly block the solvation of cellulose chains by water molecules, limiting the contact of water-soluble catalysts with glycosidic bonds in cellulose.

\subsection{Solvent effects on lignin solubility}

The development of highly selective enzymes has triggered intensive research on pretreatment and enzymatic hydrolysis of biomass. ${ }^{[17,179]}$ In light of the importance of cellulose accessibility for enzymatic hydrolysis, partial removal of lignin and hemicellulose and, in some cases, partial depolymerization of cellulose were explored as possibilities to increase accessibility. ${ }^{[21,32,174,180-182]}$ Although the contribution of lignin and hemicellulose removal to cellulose accessibility are widely argued, lignin has been considered as a major source of biomass's recalcitrance to deconstruction. ${ }^{[183]}$ Either lignin removal or lignin delocalization has been shown to create micro- and macropores that facilitate the access of enzymes to the cellulose surface. ${ }^{[23,184-188]}$ Lignin removal is also thought to play a major role in several GVL-based non-enzymatic deconstruction processes that reported higher furan or sugar yields than their aqueous counterparts ${ }^{[15,109]}$ (Table 2). In the lignin structure (Figure 2), the presence of both nonpolar (such as aromatic rings, methoxy groups, and ether linkages) and polar functional moieties (such as hydroxyl, carbonyl, and aldehyde groups) leads to lignin having a medium polarity. Based on its structural features and this polarity, two major steps are required to efficiently remove lignin: (1) lignin depolymerization into small fragments to facilitate its dissolution and (2) the dissolution of lignin in a medium-polarity solvents (e.g., acetone, ethanol, and THF) rather than very polar solvent (e.g., water) or a nonpolar solvent (e.g., hexane).

Many biomass pretreatment methods were reported, but have shown varying performances with respect to lignin removal. The comparison of lignin removal for aqueous dilute acid and acidic organic solvent-based pretreatments, which use solvents such as alcohol, acetone, THF, and GVL mixed with water, shows that the solvent typically leads to a signifi- cant increase in lignin removal ranging from $<20 \%$ to $>70 \%$ (Table 1). ${ }^{[32,51]}$

Experimental observations and measurements during aqueous dilute acid hydrolysis or pretreatment methods have shown that lignin is rarely removed and dissolved in water using these methods. ${ }^{[25-27,189]}$ Although the ether linkages in lignin can be cleaved in aqueous environments, the watersoluble depolymerized fragments will rapidly deposit on the surface of fibers and self-condense, thereby reducing accessibility to the cellulose surface. ${ }^{[25,190]}$ Continuous dissolution of depolymerized lignin fragments and/or lignin condensation products in organic solvents facilitates the transfer of catalysts to the native lignin surface, which further drives lignin removal. Recently, Luterbacher et al. reported a non-enzymatic biomass saccharification process using $80 \% \mathrm{GVL}$ and $20 \%$ water as a solvent. ${ }^{[79]}$ It was found that at a temperature of $170{ }^{\circ} \mathrm{C}$, lignin was removed very quickly prior to the dissolution and depolymerization of cellulose and hemicellulose in a flow reactor. The high yields of sugars (70-90\%) were attributed in part to the nearly complete removal and dissolution of lignin. Furthermore, the use of a biomass flow-through reactor (i.e., where the solvent flows through immobilized biomass) continuously washed away depolymerized lignin fragments, leaving a fresh lignin surface so that additional depolymerization reactions could take place. ${ }^{[15,191]}$ Further study revealed that GVL can rapidly remove and solubilize over $70 \%$ of lignin even at temperatures below $120^{\circ} \mathrm{C} .{ }^{[79]}$ Fast dissolution of lignin in GVL could be caused by multiple factors. First, the medium-polarity of the GVL-water solvent system is ideal for dissolving depolymerized lignin fragments. Second, lignin depolymerizes in GVL more rapidly than in other solvents (including ethanol or THF). At mild temperatures, this enhanced depolymerization rate could be explained by the increased activity of destabilized

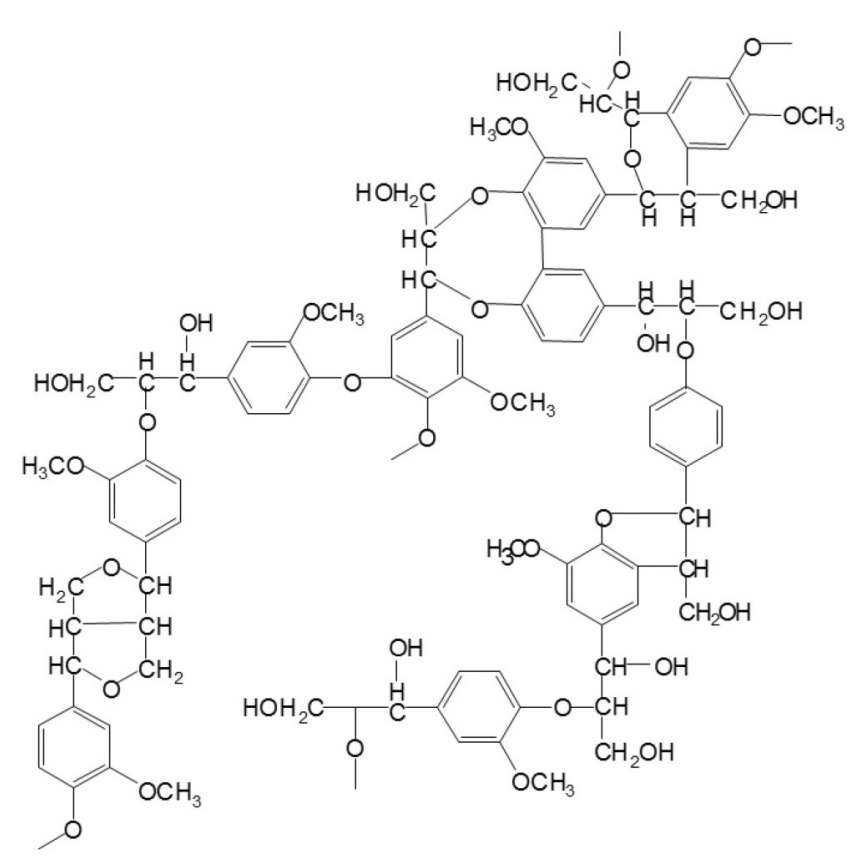

Figure 2. A representive structure of lignin in native biomass. 
proton ions in cleaving the ether linkages of lignin. Destabilized proton ions, which reduce the activation energy of a proton-catalyzed reaction, were proposed as a key factor in explaining increased cellobiose hydrolysis and xylose dehydration rates in the GVL-water solvent system. ${ }^{[5,130]}$ This effect is discussed further in the next section, which covers solvent effects on reaction rates.

The solvents involved in organosolv pretreatment and nonenzymatic processes were also used as solvents for the depolymerization and upgrading of isolated or native lignin. ${ }^{[4,192-194]}$ $\mathrm{Xu}$ et al. recently reviewed lignin conversion strategies ${ }^{[195]}$ and showed that many studies give rise to high-yield conversion of lignin model compounds into lignin monomers in the aqueous phase using acid/alkali hydrolysis and hydrogenolysis. However, the authors also show that these strategies did not perform well in the depolymerization of real lignin. Yan et al. performed hydrogenolysis on model lignin dimers and obtained a nearly $100 \%$ yield of the corresponding alkanes. ${ }^{[127]}$ However, the same authors only obtained a total yield of about $45 \%$ monomers and dimers when using a $\mathrm{Pt} / \mathrm{C}$ catalyst in the aqueous phase with native lignin in birch wood. ${ }^{[127]} \mathrm{A}$ major reason for this difference is that both native lignin and the catalyst are in the solid phase, which limits the mass transfer between the lignin reactant and the active sites of the heterogeneous catalyst. ${ }^{[194]}$ Therefore, the use of a homogeneous liquid solution of lignin $^{[4,192-194]}$ and/or a homogeneous catalyst ${ }^{[195,196]}$ was shown to further favor lignin depolymerization. Organosolv lignins, which can be dissolved by solvents such as acetone, ethanol, methanol, and THF, are relatively attractive substrates for upgrading. Using other types of isolated lignin, such as Kraft lignin, acidic lignin, and residual lignin after enzymatic hydrolysis, which usually condense in the separation process and cannot be completely solubilized except in basic environments, typically show lower conversions and yields of monomers or dimers. ${ }^{[197]}$ Wang et al. reported a way to convert organosolv lignin into arenes and alkanes using Ni-based heterogeneous catalysts in 2-propanol. ${ }^{[198]}$ They found that the methoxy and phenolic functionalities of lignin were removed while significant increases in the signals of aliphatic and arenic compounds were observed using 2D C-H NMR spectroscopy. In a recent work by Luterbacher et al., lignin could be extracted from corn stover using our GVL-based carbohydrate production platform and re-dissolved in THF and upgraded to lignin monomers through hydrogenolysis over Ru/C. ${ }^{[79]}$ Yields of up to $48 \%$ monomers were obtained. We attributed these yields, which were comparable to those obtained with native lignin, to the fact that lignin could be extracted at temperatures below $120^{\circ} \mathrm{C}$, which limited its degradation and repolymerization and allowed its re-dissolution. Alternatively, the depolymerization of water-insoluble lignin in the aqueous phase with homogenous catalysts has also been successfully investigated. Recently, Sels' group also reported monomer yields of over $50 \%$ from direct hydrogenolysis of real biomass in methanol using $\mathrm{Ru} / \mathrm{C}^{[86,87]}$ Although the direct hydrogenolysis of native lignin can avoid its condensation, which generally occurs under acidic conditions, the stability and recovery of the catalyst are major issues related to this type of technique. Recently,
Rahimi and co-workers demonstrated that they could oxidize and depolymerize water-insoluble enzymatically isolated aspen lignin under mild conditions in aqueous formic acid, which resulted in a yield over $60 \%$ of low molecular weight aromatic compounds. ${ }^{[197]}$ In summary, increasing mass transfer between lignin reactants and catalytic sites using solubilized lignin or homogenous catalysts led to enhancements in the conversion of lignin and the yields of lignin monomers and dimers, suggesting that it is a promising area for future research.

ILs were also shown to solubilize lignin. In certain IL pretreatment methods, over $80 \%$ of the original lignin was removed. ${ }^{[53-55]}$ The effect of the anion and cation on the dissolution of lignin was examined by Pu et al. ${ }^{[199]}$ They found that up to $20 \%$ of isolated Kraft pine lignin could be dissolved in 1hexyl-3-methylimidazolium trifluoromethanesulfonate ([HMIm] $\left.\left[\mathrm{CF}_{3} \mathrm{SO}_{3}\right]\right)$, 1-methyl-3-methylimidazolium methylsulfate ([MMIm] $\left.\left[\mathrm{MeSO}_{4}\right]\right)$, and 1-butyl-3-methylimidazolium methylsulfate $\left([\mathrm{BMIM}]\left[\mathrm{MeSO}_{4}\right]\right)$. For the $\left[\mathrm{BMIm}^{+}\right.$-containing ILs, the order of lignin solubility for varying anions was: $\left[\mathrm{MeSO}_{4}\right]^{-}>$ $\mathrm{Cl}^{-} \approx \mathrm{Br}^{-} \gg\left[\mathrm{PF}_{6}\right]^{-}$. All studied ILs containing large non-coordinating anions such as $\left[\mathrm{BF}_{4}\right]^{-}$and $\left[\mathrm{PF}_{6}\right]^{-}$exhibited no or very limited ability to dissolve the residual softwood kraft lignin. This indicated that the solubility of lignin was principally influenced by the nature of the anions. A shift of $\delta=0.1$ to $1.9 \mathrm{ppm}$ in the ${ }^{13} \mathrm{C}$ MMR signals was observed for lignin in ILs in comparison to ${ }^{13} \mathrm{C}$ NMR data of lignin in dimethyl sulfoxide (DMSO), which indicated that the dissolution of lignin might be attributed to the hydrogen bonding between the lignin and ILs. ${ }^{[199]}$ Besides, Jessop's group demonstrated that switchable solvents can be used to extract phenol compounds from bio-oil. ${ }^{[200]}$ This work could be further investigated to develop switchable solvents to extract lignin from biomass.

\subsection{Solvent effects on cellulose solubility}

Solubilizing cellulose has long been of interest to researchers. In the textile industry, solvent complexes such as Cuoxam $\left(\left[\mathrm{Cu}^{\prime \prime}\left(\mathrm{NH}_{3}\right)_{4}\right](\mathrm{OH})_{2}\right){ }^{\left[{ }^{[201-203]}\right.}$ dimethyl sulfoxide (DMSO)/LiCl or dimethylacetamide(DMAC)/LiCl, ${ }^{[204,205]}$ and $\mathrm{N}$-methylmorpholine$\mathrm{N}$-oxide (NMMO), ${ }^{[205-207]}$ have been widely used as solvents for dissolution of cellulose. In the last decade, ILs were found to be more powerful and environmentally friendly cellulose-dissolving solvents. ${ }^{[208]}$ The mechanism of cellulose dissolution in IL systems is similar to that in traditional cellulose solvents in the textile industry. ${ }^{[208-211]}$ These solvents all contain strong cations and anions, which can disrupt hydrogen bonding easily and form stronger hydrogen bonds with the hydroxyl groups of cellulose than those present in cellulose's original structure. The structures of common cellulose solvents and the dissolution mechanism of cellulose are summarized in Figure 3. Similar to lignin dissolution in ILs, mechanistic studies indicate that the anion affects the dissolution of cellulose by forming hydrogen bonds with cellulose hydroxyl groups. ${ }^{[74]}$ Researchers also found that the cation of ILs can significantly affect the solubility of cellulose and is controlled by (1) the nature of the functional group, (2) the cation size, and (3) the attached side-chain moiety. ${ }^{[212]}$ These three factors affect the ability of the cation to 
(a)

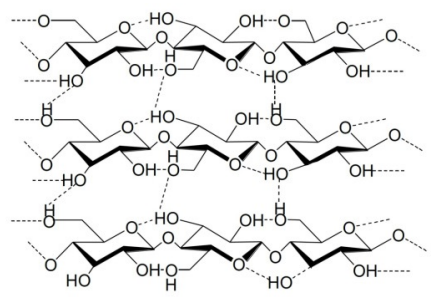

(b)

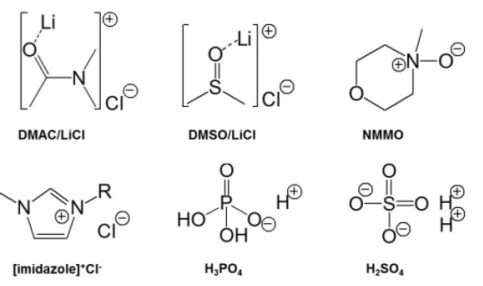

(c)
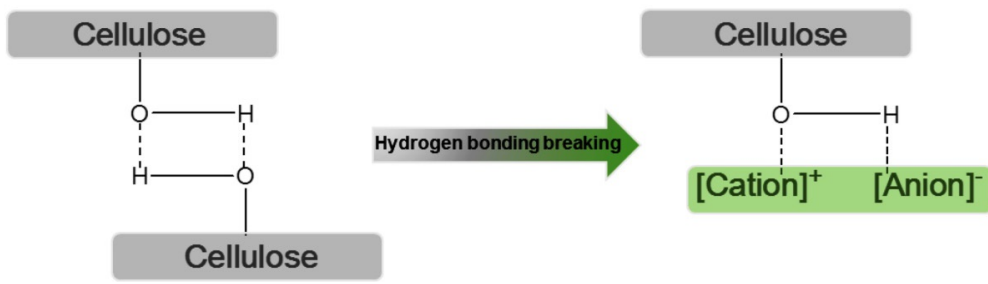

Figure 3 . Cellulose dissolution $\mathrm{m}$
the cellulose solvents. ${ }^{[204,207,208,210]}$

coordinate with the hydroxyl group's oxygen atom, form bonds, and diffuse to cellulose crystalline. All three of these effects control the dissolution of cellulose. More details can be found in the recent review by Badgujar and Bhanage, which extensively covers the role of IL cations and anions in the dissolution of lignocellulosic biomass. ${ }^{[212]}$

As discussed above, the dissolution of cellulose requires the disruption of the crystalline structure of the cellulose and the solvation of cellulose chains. Concentrated acid hydrolysis ${ }^{[62,64]}$ and phosphoric acid pretreatment ${ }^{[213]}$ are well-known methods to swell and dissolve cellulose in aqueous solutions. In concentrated acid solutions, hydrogen bonds in the cellulose crystalline structure are disrupted by the large amount of unsolvated proton ions that are present. These ions can form stronger hydrogen bonds with the hydroxyl groups of cellulose than with themselves. ${ }^{[6]]}$ However, this type of method faces issues of corrosion and acid recovery, limiting its application in industry.

Compared to traditional cellulose solvents, an advantage of ILs is that they can be tailored to dissolve different molecules by changing the structures of their cations and anions. Based on the feasibility of dissolving both cellulose and lignin, IL saccharification processes and IL pretreatment methods have been developed. ${ }^{[16,21]}$ However, the presence of water in the ILs can inhibit the dissolution of biomass because water molecules can disrupt the hydrogen bonds between the ions of the IL and the hydroxyl groups of cellulose. Research results by Swatloski and co-workers indicated that water molecules competed with IL anions for hydrogen bond formation processes and subsequently interrupted the dissolution process. ${ }^{[210]}$ Even the presence of $1 \%$ water hampered the dissolution process significantly. ${ }^{[210]}$ However, Brandt et al. showed that the presence of trace amounts of water was necessary to guarantee swelling/dissolution of lignocellulosic biomass. ${ }^{[72]}$ Therefore, the influence of water content may depend on the type of IL used for biomass processing. ${ }^{[7]}$ In any case, a strict control of the water content is required when using ILs as solvent for biomass processing. Binder and Raines ${ }^{[16]}$ developed a method for hydrolyzing biomass into sugars in ILs. A high yield of $90 \%$ was obtained in this method, but a continuous addition of water during the whole hydrolysis process was required. The dissolution of cellulose was performed first at low water contents, and then cellulose glyosidic bonds were cleaved through hydrolysis at a higher water content. ${ }^{[16]}$ Degradation of sugars was limited because the dissolution of cellulose had lowered the activation energy $\left(\Delta G_{\text {act }}\right)$ for cellulose hydrolysis, enabling it to proceed at lower temperatures $\left(105^{\circ} \mathrm{C}\right)$ compared to crystalline cellulose (Figure 4). However, long residence times, sep-

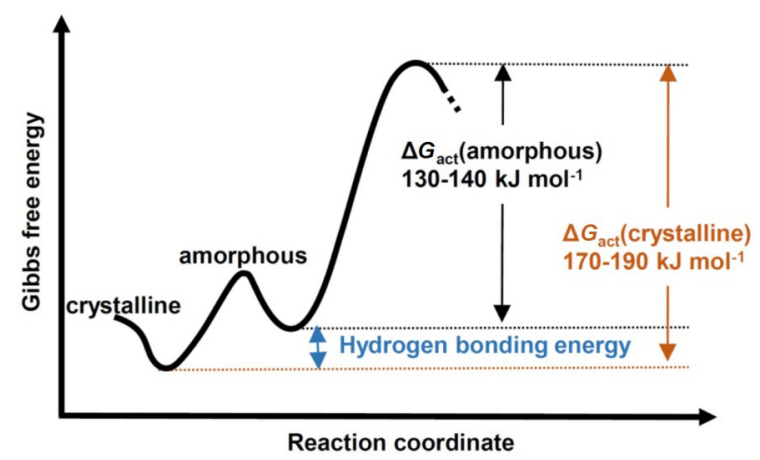

Figure 4. Energy diagram for the hydrolysis of crystalline cellulose and amorphous cellulose. ${ }^{[60]}$

aration of sugars, purification, dewatering, and recycling of ILs are barriers to industrial implementation of this process. In contrast, most of the IL used during pretreatment can be directly recovered by solid-liquid separation. ${ }^{[2]]}$ However, pretreatment methods still require subsequent hydrolysis with enzymes and also suffer from the high cost of ILs. ${ }^{[7]}$

Another simple method of disrupting cellulose hydrogen bonding is increasing the reaction temperature to overcome the energy barrier of breaking hydrogen bonds. Increasing temperature leads to depolymerization and dissolution of cel- 


\begin{tabular}{|c|c|c|c|c|c|}
\hline Substrate & $\begin{array}{l}\text { Reaction } \\
\text { temperature } \\
{\left[{ }^{\circ} \mathrm{C}\right]}\end{array}$ & $\begin{array}{l}\text { Acti } \\
\text { cellulose } \\
\text { hydrolysis }\end{array}$ & $\begin{array}{l}\text { /ation energ } \\
\text { cellobiose } \\
\text { hydrolysis }\end{array}$ & $\begin{array}{l}{\left[\mathrm{kJ} \mathrm{mol}{ }^{-1}\right]} \\
\text { glucose de- } \\
\text { composition }\end{array}$ & Ref. \\
\hline filter paper & $200-240$ & 178.9 & 138 & 137.2 & [60] \\
\hline douglas fir & $170-190$ & 179.5 & & 137.5 & [59] \\
\hline kraft paper & $180-240$ & 188.7 & & 137.2 & [61] \\
\hline $\begin{array}{l}\text { municipal } \\
\text { solid wastes }\end{array}$ & $200-240$ & 171.7 & & 142.4 & [58] \\
\hline
\end{tabular}

lulose, but it can reduce selectivity to sugars and cause downstream issues resulting from sugar-derived degradation products. ${ }^{[57,62,65,214]}$ Table 4 summarizes kinetic results of cellulose conversion in aqueous dilute-acid solutions. Kinetic studies showed that, for cellulose hydrolysis into glucose, the activation energy is $171-189 \mathrm{~kJ} \mathrm{~mol}^{-1}$, which is considerably higher than the activation energy of $130-140 \mathrm{~kJ} \mathrm{~mol}^{-1}$ for the decomposition of cellobiose into glucose or glucose into HMF and levulinic acid. ${ }^{[208-211]}$ The high activation energy associated with crystalline cellulose hydrolysis is thought to be linked to the high energy input required to break the hydrogen bonds ${ }^{[208-211]}$ (Figure 4). Because of this difference in activation energy, sugar degradation will outpace cellulose hydrolysis at lower temperatures. Evidence shows that this difference in rates could reverse at high temperatures $\left(>250{ }^{\circ} \mathrm{C}\right) .{ }^{[132,215]}$ However, these temperatures require impractical residence times $(<$ a few seconds) to achieve high sugar yields.

\subsection{Solvent effects on the solubility of HMF or furfural}

There has been great interest in producing HMF from fructose, glucose, and directly from biomass. ${ }^{[2]}$ Research results have shown that producing HMF from fructose leads to higher rates and selectivities because the five-membered ring of fructose can directly dehydrate into $\mathrm{HMF}^{[2]}$ During the conversion of glucose to HMF, the pyranose form of glucose is believed to transform into the furanose form before dehydration. ${ }^{[2]}$ This step has the highest energy barrier and is considered to be the rate-limiting step in glucose dehydration. ${ }^{[2]}$ To overcome this high activation barrier, higher reaction temperatures or catalysts were used. ${ }^{[93,216-218]} \mathrm{HMF}$ is fairly unstable and tends to polymerize with sugars or itself to form humins even at mild temperatures, leading to low selectivities, which in turn reduces selectivity to $\mathrm{HMF}^{[219]}$ Increasing reaction temperatures will accelerate not only the dehydration of sugars but also the degradation of HMF, which limits the effect of the temperature on the increase in HMF selectivity. Similarly, catalysts can often improve the conversion of glucose but cannot stabilize HMF.

One of the most successful methods to prevent the condensation of HMF was to reduce its concentration by selective extraction. A number of research groups combined the dehydration of sugars to HMF in the aqueous phase with its simultaneous extraction in an organic phase (Figure 5). ${ }^{[220]}$ Peniston first demonstrated a continuous extraction system for producing HMF from carbohydrates using butanol as the organic

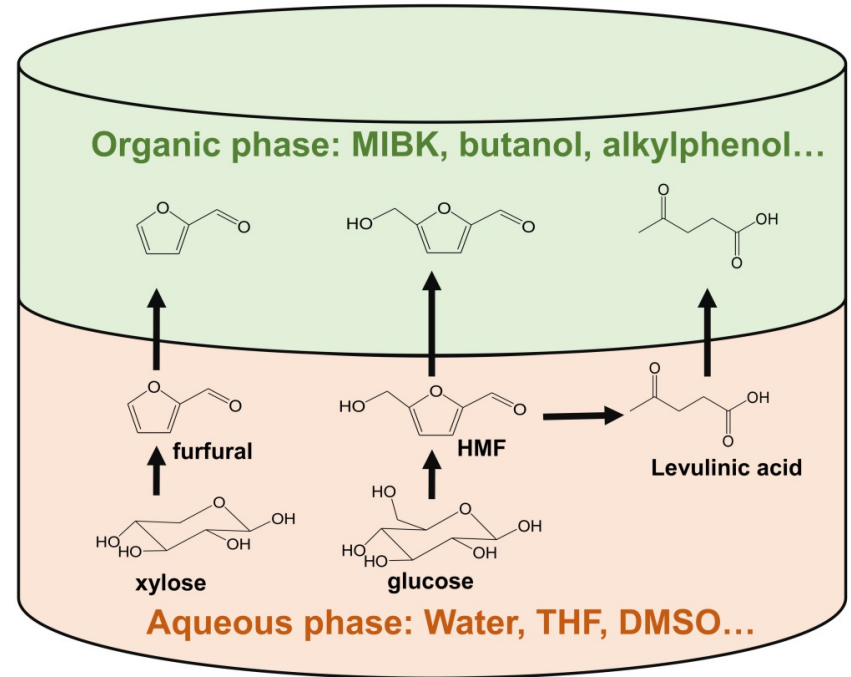

Figure 5. Biphasic extraction system for the dehydration of carbohydrates into HMF, furfural and levulinic acid. Adapted from Luterbacher et al. ${ }^{[3]}$

phase. ${ }^{[221]}$ Kuster and Van der Steen used methyl isobutyl ketone (MIBK) as the organic phase and found that extending the reaction time led to increased HMF yields without decreasing the selectivity. An increase in the MIBK/water ratio could further increase the yield and selectivity of HMF. ${ }^{[222]}$

In recent years, Dumesic and co-workers performed extensive research to improve biphasic reaction systems using MIBK, butanol, alkylphenols, and DMSO as solvents. ${ }^{[9,13,20]}$ They found that HMF yields could be significantly improved by modifying the aqueous phase with DMSO and the MIBK phase with 2-butanol and obtained HMF selectivities as high as $85 \%$ at a fructose conversion of $95 \%$. The selectivity of HMF increased with the decrease of fructose concentration, the increase of DMSO or $\mathrm{N}$-methyl-2-pyrrolidone (NMP) content, and the increase of the amount of extracting solvent. ${ }^{[13]}$ They also demonstrated that the presence of $\mathrm{NaCl}$ increased the partition coefficient of HMF in biphasic systems, thus increasing HMF selectivity by removing it more efficiently from the reactive aqueous solution. ${ }^{[11]}$ Different salts showed different degrees of salting out effects on the biphasic system, therefore leading to varied selectivities. ${ }^{[222]}$ Through this extraction technique, the residence time of HMF in the aqueous phase could be minimized to suppress humin formation. A comprehensive review on HMF production from biomass has been done by Putten et al. ${ }^{[2]}$ Similarly, furfural, xylose's dehydration product, which suffers from similar polymerization issues, ${ }^{[223]}$ was shown to benefit from extractive systems. Gürbüz et al. showed that when 2-sec-butylphenol (SBP) was used as an extraction solvent, a furfural selectivity of $82 \%$ and a yield of $71 \%$ could be attained. ${ }^{[9]}$ In another work, using microwave heating with MIBK as the organic phase, a furfural yield of $85 \%$ was obtained from glucose compared to a $30 \%$ yield in the monophasic aqueous system. ${ }^{[105]}$ Lange et al. recently published a review on furfural production from lignocellulosic biomass, which provides more details on its production. ${ }^{[224]}$

In summary, for the conversion of lignocellulosic biomass, the literature reviewed above demonstrates that dramatically 
increasing mass transfer rates between biomass (a solid) and the catalysts (homogeneous or heterogeneous) using an organic solvent can significantly increase reaction rates and conversion. A solvent system that solubilizes one biomass component can significantly enhance the conversion rates of others by increasing their accessibility. A typical example is the enhanced conversion of cellulose, either by acid or enzymes, after removal of lignin. Nevertheless, it is often beneficial to tailor a solvent system to the particular application. For example, for the conversion of sugars into furanic compounds, decreasing the solubility of furanics can be beneficial because it can suppress the condensation and improve selectivity. However, the effect of the solvent can go far beyond its effect on solubility. In the following section, we will review how the solvent effects can affect the thermodynamics of the various moieties participating in the reaction and thereby change the rates and selectivities of these reactions.

\section{Solvent Effects on Chemical Thermo- dynamics}

The chemical thermodynamics of a reaction are often an important tool used by researchers to control reaction rates and product selectivity. The entire field of catalysis is based on controlling the free energy of the transition state and reducing the activation energy of one or several reaction steps. Similarly, solvent effects can be used to control the thermodynamic states of the various moieties participating in the reaction. In a solvent system, the thermodynamics of a solute will be significantly influenced by solvent-solute intramolecular interactions. In this way, the solvent system can modify the free energy of the reactants, transition state(s), products, and even the catalyst, which are all solutes.

Therefore, a solvent system can be used to accelerate reaction rates by changing the activation energy between the reacting molecules (including the catalyst) and the transition state. Below, we discuss reports of solvent effects on the catalyst and then review effects on the reactants. Of course, a major thermodynamic effect that solvents have on the reactants is their dissolution, which was discussed in the previous sections. Following this, we cover studies that describe solvent effects on the transition state. Finally, a solvent system can also be used to improve selectivity by stabilizing or favoring certain products by lowering their free energy. Therefore, we finish by discussing solvent effects on reaction products

\subsection{Solvent effects on catalyst}

There have been numerous studies of organic solvent effects on biomass conversion reaction kinetics in recent years. Phan et al. ${ }^{[225]}$ found that the hydrolysis rates of the glyosidic bonds in 1,4-dioxane-water mixtures were significantly enhanced by the presence of $\mathrm{Cl}^{-}$and $\mathrm{Br}^{-}$ions. $\mathrm{Br}^{-}$anions were proposed to catalyze the breaking of glycosidic bonds through nucleophilic attacks, and their effect was even more pronounced in $74 \%$ and $82 \%$ 1,4-dioxane-water mixtures. The increased glucose yields were attributed to the reduced solvation of anions in the 1,4-dioxane-water solvent systems. They proposed that the solvation of $\mathrm{Br}^{-}$and $\mathrm{Cl}^{-}$decreased with the increase of the 1,4-dioxane content, leading to an increased nucleophilicity of the ions. ${ }^{[225]}$

Similar solvent effects on the catalyst's activity were observed in polar aprotic solvent systems when acids were used as dehydration catalysts. Reports have shown that the standard Gibbs free energies of protons significantly varied between water and organic solvents (Table 5). For example, the

\begin{tabular}{|lcr|}
\hline \multicolumn{2}{|c|}{ Table 5. Free energies of solvation for protons in different solvents. } \\
\hline Solvent & $\Delta G_{\mathrm{s}}(\mathrm{H}+)\left[\mathrm{kcal} \mathrm{mol}^{-1}\right]$ & Ref. \\
\hline $\mathrm{H}_{2} \mathrm{O}$ & -265.9 & \\
$\mathrm{CH}_{3} \mathrm{OH}$ & -263.5 & \\
$\mathrm{CH}_{3} \mathrm{CN}$ & -260.2 & \\
DMSO & -273.3 & \\
\hline
\end{tabular}

free energy of solvation of a proton changed from $1113 \mathrm{~kJ} \mathrm{~mol}^{-1}$ in water to $1089 \mathrm{~kJ} \mathrm{~mol}^{-1}$ in an aprotic solvent such as acetonitrile. This decrease of free energy of $24 \mathrm{~kJ} \mathrm{~mol}^{-1}$ in acetonitrile leads to a higher reactivity of said proton. ${ }^{[26]}$ However, in DMSO, the same proton was stabilized because of the higher Lewis basicity of DMSO compared to water. Lower values of $\Delta G$ were also found when solvating metal ions in DMSO compared to water in the following order: $\mathrm{Li}^{+}<\mathrm{Cs}^{+}<$ $\mathrm{Na}^{+}<\mathrm{K}^{+}<\mathrm{Rb}^{+}$(least negative and most destabilized by DMSO). This order was consistent with the solvation of these same metal ions in water, indicating that DMSO is a unique polar aprotic solvent that, like water, showed weak Lewis basicity. ${ }^{[229]}$ It was notable that the strong co-ordination between DMSO and $\mathrm{Li}^{+}$released free anions, which explained the excellent performances of the $\mathrm{DMSO} / \mathrm{LiCl}$ system as a good solvent system for anion-catalyzed reactions such as cellulose dissolution and glucose dehydration into $\mathrm{HMF}^{[6,93,204,230]}$

Mellmer et al. also studied the effects of polar aprotic solvents (e.g., THF, GVL, and dioxane) on a variety of acid-catalyzed biomass conversion reactions and compared these solvent effects to reactions performed in water. ${ }^{[5,130]}$ Significant increases in turnover frequencies (TOFs) for the dehydration of xylose to furfural were observed in the presence of the organic solvents (Table 6). They proposed that the polar aprotic solvent

\begin{tabular}{|c|c|c|c|}
\hline Solvent ${ }^{[b]}$ & Catalyst ${ }^{[c]}$ & $T[\mathrm{~K}]$ & TOF $\left[\mathrm{ks}^{-1}\right]$ \\
\hline $\mathrm{H}_{2} \mathrm{O}$ & SA & 448 & $1.5 \pm 0.05$ \\
\hline GVL & SA & 448 & $46 \pm 2$ \\
\hline dioxane & SA & 448 & $21 \pm 1$ \\
\hline $\mathrm{H}_{2} \mathrm{O}$ & PSA & 448 & $2.6 \pm 0.2$ \\
\hline GVL & PSA & 448 & $25 \pm 1$ \\
\hline $\mathrm{H}_{2} \mathrm{O}$ & SA & 418 & $0.090 \pm 0.01$ \\
\hline GVL & SA & 418 & $5.1 \pm 0.2$ \\
\hline THF & SA & 418 & $1.2 \pm 0.09$ \\
\hline
\end{tabular}

[a] Table was adapted from Refs. $[5,130]$. [b] Organic solvents contained 10 wt $\% \mathrm{H}_{2} \mathrm{O}$. [c] SA: sulfuric acid; PSA: propylsulfonic acid. 
(a)

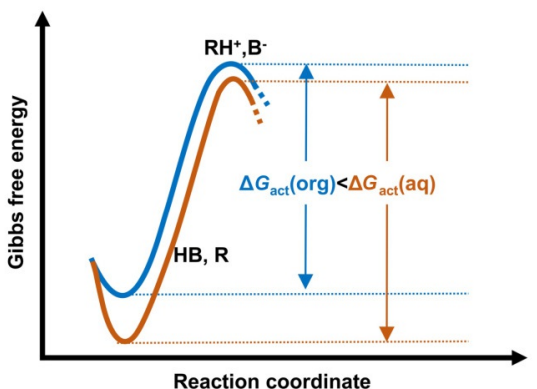

(b)

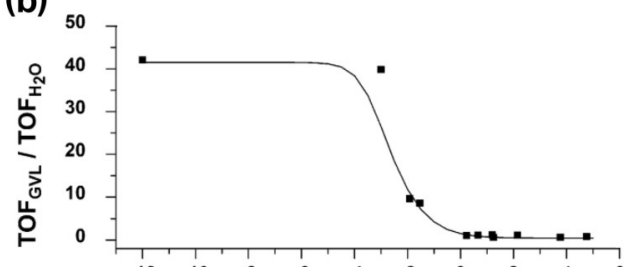

Figure 6. (a) Destabilization of the proton in water and organic solvents; (b) ratio of TOFs for xylose conversion in $\mathrm{H}_{2} \mathrm{O}$ and $\mathrm{GVL}$ (which contained $10 \% \mathrm{H}_{2} \mathrm{O}$ ) using homogeneous Brønsted acid catalysts with different $\mathrm{p} K_{\mathrm{a}}$ values. Part (b) was taken from Mellmer et al. ${ }^{[130]}$

affected the stabilization of the acidic proton relative to the protonated transition states, leading to accelerated reaction rates for these acid-catalyzed reactions (Figure $6 \mathrm{a}$ ). They further demonstrated the dominant effect of the destabilization of the acidic proton by showing that this destabilization led to significant recombination of the proton with its counterion for weak acids. Because of the resulting decrease in concentration of the acid catalyst, dehydration rates were actually slower in the GVL-water system compared to pure water when they were catalyzed by weak acids (Figure $6 \mathrm{~b}$ ). ${ }^{[5,130]}$

As discussed above, adding DMSO was shown to improve the production of furans from sugars. ${ }^{[11,13]}$ Qian et al. conducted a theoretical study on glucose dehydration in DMSO and showed that glucose isomerization and dehydration depended strongly on the solvent because of the competition between cellulose hydroxyl groups and solvent molecules for protons. ${ }^{[129,218]}$ They found that the higher the solvent's affinity for the proton, the more difficult it was for the hydroxyl groups on glucose to compete for the solvent's proton and thus a higher activation barrier was expected. The proton was highly stabilized by water clusters due to the extensive hydrogen-bonding network formed in aqueous solutions. In this case, the barrier for glucose dehydration reaction was high and largely solvent induced. The authors argued that protonation of the $\mathrm{C} 2-\mathrm{OH}$ group on glucose led to the formation of HMF through an isomerization reaction to fructose followed by dehydration reactions, whereas protonation of $\mathrm{C} 1-\mathrm{OH}$ led to the formation of humins (Figure 7). In DMSO, the overall barrier for protonation of $\mathrm{C} 2-\mathrm{OH}$ and breakage of the $\mathrm{C} 2-\mathrm{O}$ bond was only about $20 \mathrm{kcal} \mathrm{mol}^{-1}(1 \mathrm{kcal}=4.18 \mathrm{~kJ})$, which was significantly lower than the barrier of $35 \mathrm{kcal} \mathrm{mol}^{-1}$ observed for the protonation of $\mathrm{C} 2-\mathrm{OH}$ and breakage of $\mathrm{C} 2-\mathrm{O}$ in water. This calculation was consistent with the reports that ions such as protons, $\mathrm{Br}^{-}$or $\mathrm{Cl}^{-}$were less solvated and, therefore, destabilized in organic solvents. ${ }^{[130,225]}$ but inconsistent with the result discussed in the last paragraph that protons were more stabilized in DMSO compared to water. ${ }^{[226]}$

\subsection{Solvent effects on the reactants}

In contrast to the effect of DMSO on proton affinity discussed above, Qian et al. also found that the atomic charges on glucose's $\mathrm{C}$ and $\mathrm{O}$ atoms changed in $\mathrm{H}_{2} \mathrm{O}$ inversely compared to changes in DMSO, indicating that the DMSO and $\mathrm{H}_{2} \mathrm{O}$ solvents affected the charge distributions in glucose very differently. These differences in charge were thought to contribute to the differences in reactivity of glucose between these two solvents. ${ }^{[128,218]}$ The author's calculations indicated that the solvent was likely to affect the thermodynamics of the reactants. A more reactive form of glucose would have an effect similar to a more reactive catalyst and reduce the activation energy (analogous to what is shown in Figure 6). Several research reports showed that DMSO could affect the equilibrium of sugar species by promoting the formation of the furanose form of fructose. ${ }^{[216,231]}$ On increasing temperature, the furanose form of fructose increased with the decrease of the alternate pyranose form (Table 7). ${ }^{[231]}$ At high temperatures, even the usually rare $\alpha$-pyranose form was observed because the thermal energy was sufficient to overcome the anomerization barrier in DMSO. In turn, changes in these equilibria resulted in changes in the reaction rate of furanose dehydration.

Nikolakis et al. analyzed the FTIR spectra of fructose in different solvents and observed a blue shift in the $\mathrm{OH}$ stretching vibration of fructose that was thought to be caused by the increase in the strength of the hydrogen bond between fructose and the solvent. ${ }^{[232]}$ They explained that the addition of the or-

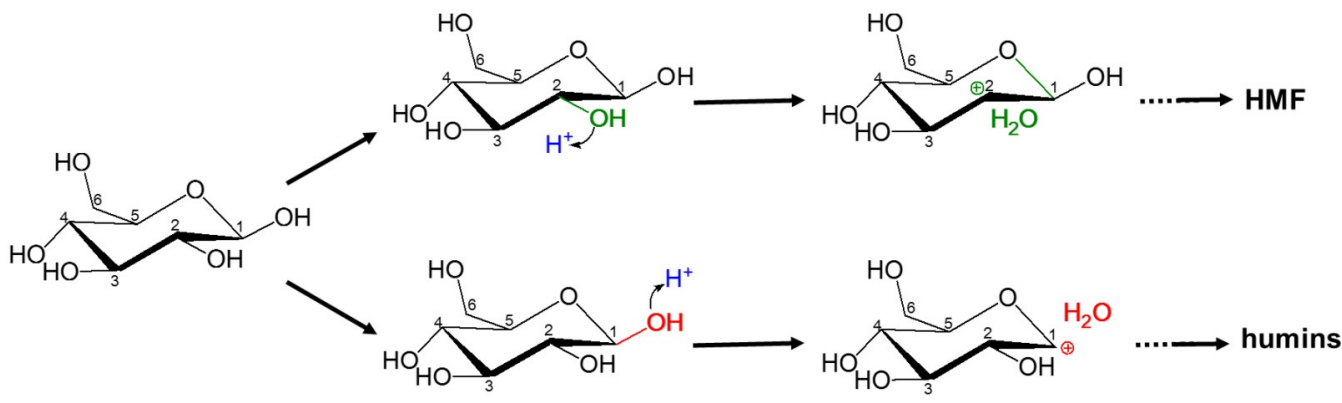

Figure 7. Glucose degradation pathways induced by protonation of different hydroxyl groups. 


\begin{tabular}{|c|c|c|c|c|c|}
\hline \multirow{2}{*}{$\begin{array}{l}T \\
{\left[{ }^{\circ} \mathrm{C}\right]}\end{array}$} & \multicolumn{4}{|c|}{ Anomeric composition [\%] } & \multirow[t]{2}{*}{ Ref. } \\
\hline & $\alpha$-pyranose & $\beta$-pyranose & $\alpha$-furanose & $\beta$-furanose & \\
\hline 20 & - & 29 & 20 & 46 & [230] \\
\hline 50 & - & 21 & 23.5 & 51 & [230] \\
\hline 23 & - & 27.7 & 20.7 & 51.6 & [216] \\
\hline 150 (1.0 min) & 4.5 & 16.1 & 24.9 & 54.5 & [216] \\
\hline 150 (3.0 min) & 4 & 21.9 & 25.9 & 48.9 & [216] \\
\hline
\end{tabular}

ganic solvent changed the hydrogen bonding environment in the first solvation shell. In water, water molecules bind to glucose molecules and to the neighboring water molecules. On addition of the organic solvent, water molecules mostly formed hydrogen bonds with glucose alone, which resulted in a stronger interaction. ${ }^{[232]}$ Vasudevan et al. found that, with the presence of an organic solvent in water, the mobility of glucose molecules was reduced, forming longer-lived hydrogen bonds with decreasing water content (Table 8). ${ }^{[131]}$ This was attributed to the increased hydrogen-bonding strength of glucose with water and with organic solvents in the presence of increasing amount of organic solvents. This effect is one of the few reported that can be classified as a dynamic solvent effect on the reaction rate rather than a static effect (see Section 3 of this Review). The reduced mobility of glucose molecules and stronger interaction with the solvent was suggested to minimize the probability of two glucose molecules or a glucose molecule and a sugar derivative such as HMF coming into close proximity to each other. This could, in turn, reduce intermolecular condensation reactions and explain reduced degradation. The authors' simulation results showed that DMSO, DMF, and THF formed a strong first solvation shell around glucose, competing with water for this space (Figure 8). The reduced probability of finding water molecules near the C3 and $\mathrm{C} 4 \mathrm{O}$ atoms suggested that, in the presence of co-solvents, there was a reduced probability of water being hydrogen bonded to these groups. Therefore, the chance of these groups getting protonated was reduced. The authors argued that undesired products such as humins formed due to the protonation of $\mathrm{C} 3$ and $\mathrm{C} 4 \mathrm{O}$ atoms, which was an alternative humin formation mechanism to the one suggested by Qian et al. ${ }^{[129,218]}$ (which suggested that the protonation of the C1 hydroxyl group would lead to humins). They further argued that organic solvent molecules near the $\mathrm{H}$ atoms of the hydroxyl groups could prevent the acid-catalyzed condensation reaction between glucose molecules.

\subsection{Solvent effects on transition state}

Through solvent-solute interactions, solvation can change the free energy of the transition state. In cases where the solvent reduces the transition state's free energy, said solvent functions as a catalyst and decreases the activation energy of the reaction, thereby increasing the reaction rate. Kunov-Kruse et al. found that ILs not only dissolved cellulose, facilitating the contact between cellulose and the catalyst, but also significantly decreased the activation energy of cleaving glyosidic
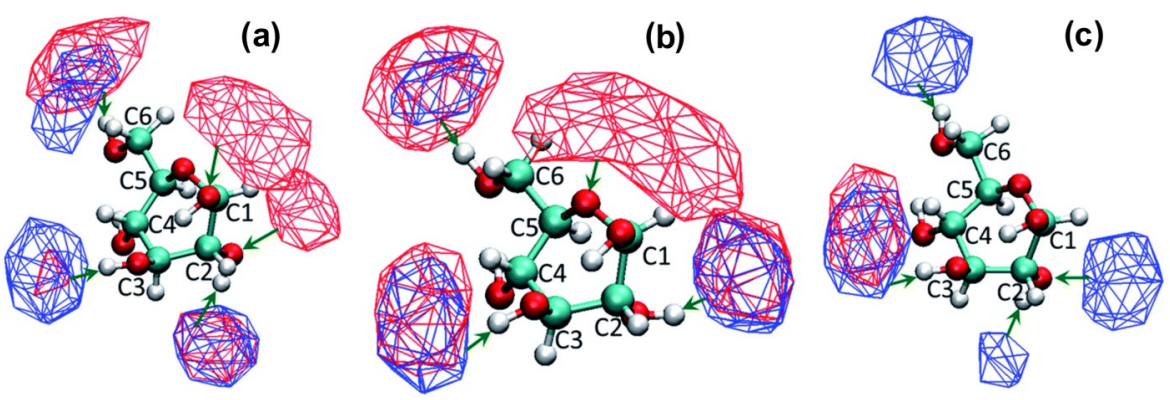

Figure 8. Volumetric spatial density maps (isosurfaces) of the time-averaged distribution of co-solvent (blue isosurfaces) and water (red isosurfaces) around glucose, in mixtures containing $10 \mathrm{wt} \%$ water and $90 \mathrm{wt} \%$ co-solvent. The co-solvents are (a) DMSO, (b) THF, and (c) DMF. Used with permission from Vasudevan and Mushrif. ${ }^{[131]}$

\begin{tabular}{|c|c|c|c|c|c|c|c|}
\hline \multirow[t]{3}{*}{ System } & \multirow[t]{3}{*}{ Hydrogen bond type } & \multicolumn{6}{|c|}{ Water content [wt \%] } \\
\hline & & \multicolumn{2}{|r|}{90} & \multicolumn{2}{|c|}{50} & \multicolumn{2}{|r|}{10} \\
\hline & & $\tau[\mathrm{ps}]$ & 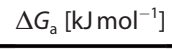 & $\tau[\mathrm{ps}]$ & $\Delta G_{\mathrm{a}}\left[\mathrm{kJ} \mathrm{\textrm {mol } ^ { - 1 } ]}\right.$ & $\tau$ [ps] & $\Delta G_{\mathrm{a}}\left[\mathrm{kJ} \mathrm{\textrm {mol } ^ { - 1 } ]}\right.$ \\
\hline \multirow[t]{2}{*}{ DMSO-water mixture } & glucose-DMSO & 23.38 & 12.34 & 60.46 & 14.7 & 410.24 & 19.44 \\
\hline & glucose-water & 6.67 & 9.23 & 13.73 & 11.02 & 61.77 & 14.75 \\
\hline \multirow[t]{2}{*}{ DMF-water mixture } & glucose-DMF & 34.83 & 13.33 & 154.94 & 17.03 & 1096 & 21.80 \\
\hline & glucose-water & 7.11 & 9.39 & 32.36 & 13.15 & 66.36 & 14.93 \\
\hline \multirow[t]{2}{*}{ THF-water mixture } & glucose-THF & 27.3 & 12.78 & 75.56 & 15.25 & 157.37 & 17.08 \\
\hline & glucose-water & 7.53 & 9.53 & 19.68 & 11.91 & 25.16 & 12.53 \\
\hline
\end{tabular}


(a)

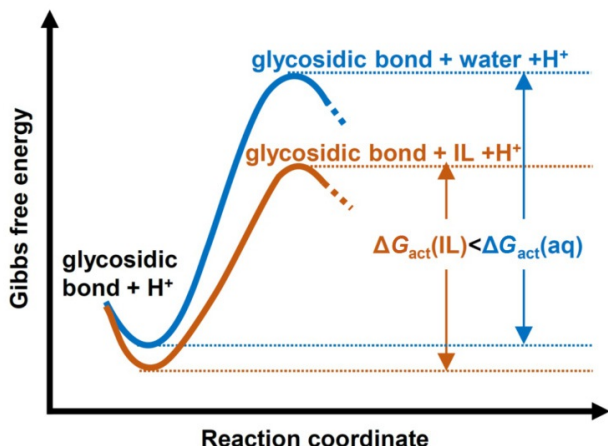

(b)

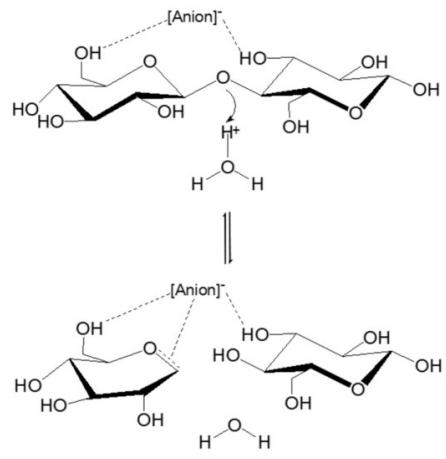

Figure 9. Cleavage of a glycosidic bond catalyzed by ILs. (a) Simplified energy diagram for the cleavage of glyosidic bonds in water and in an IL, and (b) IL-stabilized oxocarbenium ion. ${ }^{[222]}$

bonds $^{[233]}$ (Figure 9a). The apparent activation energy for the acid-catalyzed hydrolysis of glyosidic bonds in cellulose and its oligomers in the aqueous phase was around $120-130 \mathrm{~kJ} \mathrm{~mol}^{-1}$. This activation energy was considerably higher than the 50 $60 \mathrm{~kJ} \mathrm{~mol}^{-1}$ required for the formation of oxocarbenium ions in simple linear acetals and was reported to be caused by the formation of unfavorable oxocarbenium ions during the hydrolysis of cyclic glucose acetals. ${ }^{[234,235]}$ This unfavorable oxocarbenium ion could be explained structurally. The pyranose ring structure could prevent the preferred planar geometry around the $\mathrm{C}=\mathrm{O}^{+}$group. However, it was proposed that, in ILs, the strongly ionic environment stabilized the positive charge of this unfavorable oxocarbenium ion (Figure $9 \mathrm{~b}$ ). This stabilization could explain the lower activation energy of cellulose hydrolysis in ILs. ${ }^{[236,237]}$ Another report also showed that fructose could directly dehydrate into HMF in pure DMSO due to DMSO acting through a catalytic mechanism (Figure 10). One of the proposed intermediates (Compound 4, Figure 10) was identified by NMR spectroscopy. Intermediates 2 and 3 were not detected by NMR spectroscopy because they were part of an unstable activated complex. ${ }^{[216]}$ Similarly, Lai et al. studied the effect of imidazolium-based ILs on the dehydration of fructose to HMF. They found that HMF was formed from fructose at a high yield of $72 \%$ using $\mathrm{HCl}$ as the catalyst at room temperature whereas no HMF formed in other solvents. Gas-phase calculations at $298 \mathrm{~K}$ suggested that in common solvents the complete conversion of fructose to HMF was an endothermic process with a positive energy difference $\Delta E=+28.8 \mathrm{kcal}$ $\mathrm{mol}^{-1}$, indicating that the fructose dehydration reaction was thermodynamically unfavorable (Figure 11). In contrast, density functional theory (DFT) calculations that included the effect of two imidazolium molecules to mimic the presence of the solvent showed that each step was exothermal, leading to an overall negative energy difference $\left(\Delta E=-13.3 \mathrm{kcal} \mathrm{mol}^{-1}\right)$. They proposed that the role of $[\mathrm{BMIm}] \mathrm{Cl}$ was to stabilize each

(a)

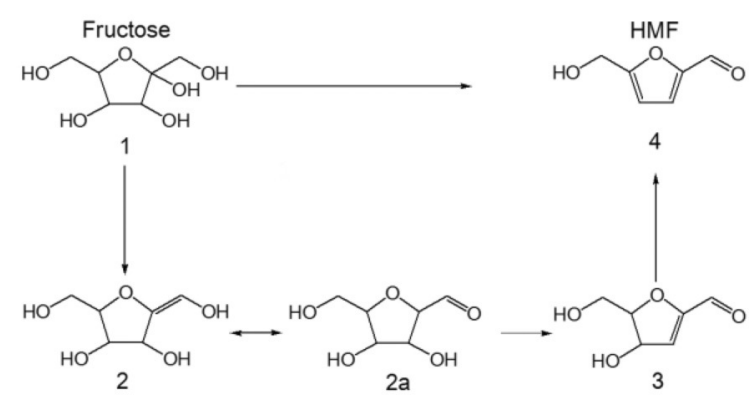

(b)
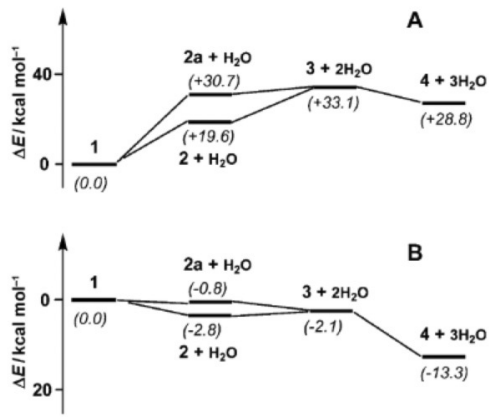

Figure 11. IL-catalyzed fructose dehydration at room temperature. (a) Proposed pathway of fructose dehydration into HMF in IL and (b) DFT calculated energy diagrams of fructose dehydration in water (A) and IL (B). Taken with permission from Lai and Zhang. ${ }^{[238]}$

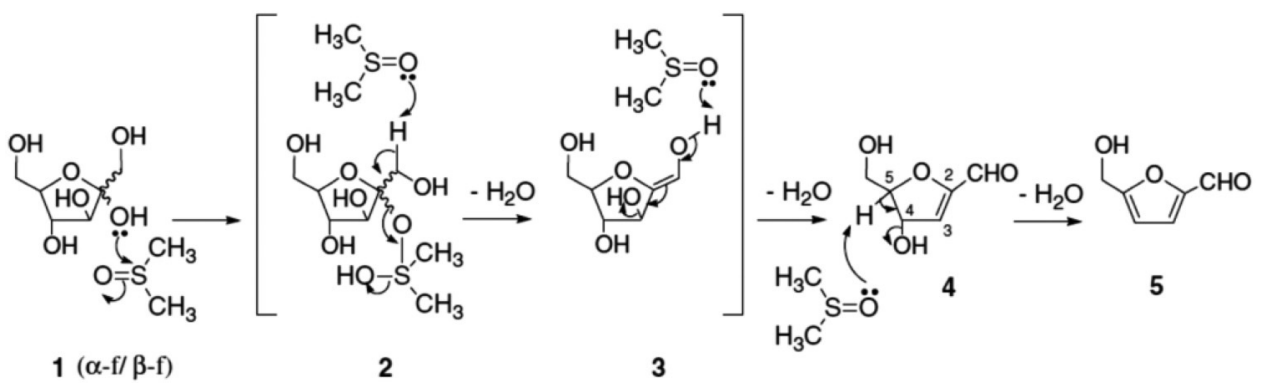

Figure 10. DMSO-catalyzed dehydration of fructose into HMF. Taken with permission from Amarasekara et al. ${ }^{[216]}$ 
intermediate and products through hydrogen bonding, enabling the reaction to proceed at ambient temperature. ${ }^{[238]}$

\subsection{Solvent effects on products}

We have discussed improving the selectivity of HMF production by using biphasic solvent systems to stabilize HMF in an organic phase away from the catalyst. Another possible way to prevent HMF self-condensation is to decrease its free energy in the solvent thereby increasing the activation energy of its condensation. Many researchers have found that HMF yields are higher when produced in a polar aprotic solvent such as DMSO, THF, or GVL compared to its production in water, with some suggesting that this was due to the stabilization of HMF in the organic solvent (Table 9). Tsilomelekis et al. clarified the resulting mechanism by performing DFT calculations. ${ }^{[128]}$ They found that DMSO binds to HMF more strongly than water and that the $\mathrm{C}=\mathrm{O}$ groups in $\mathrm{HMF}$ molecules were solvated by DMSO prior to being solvated by water in DMSO-water systems. HMF solvation by DMSO increased its LUMO energy, which reduced its susceptibility to nucleophilic attack and minimized undesirable hydration and humin-formation reactions (Figure 12). This result together with the preferential solvation of HMF by DMSO explained the enhanced HMF stability in DMSO-water mixtures observed experimentally. ${ }^{[128]}$
Mellmer et al. studied the apparent activation energies for cellobiose hydrolysis and sugar dehydration in a GVL-water solvent system. ${ }^{[5,130]}$ They found that sugars were stabilized in GVL because the increased proton activity affected the activation energies of various reactions differently. Their results showed that cellobiose hydrolysis as well as glucose and xylose conversion in $\mathrm{H}_{2} \mathrm{O}$ had similar activation energies ranging from $131-138 \mathrm{~kJ} \mathrm{~mol}^{-1}$. Accordingly, they proposed that low sugar yields from biomass had been obtained in aqueous media at these conditions because of the competition between cellulose or hemicellulose hydrolysis and the subsequent sugar conversion reactions. However, the use of GVL as a solvent increased the difference between the apparent activation energies for cellobiose hydrolysis, and glucose or xylose conversion. In the 4:1 GVL-water solvent system, apparent activation energies of 138 and $135 \mathrm{~kJ} \mathrm{~mol}^{-1}$ were observed for glucose and xylose conversion, respectively, whereas the apparent activation energy was significantly lower for the cellobiose hydrolysis reaction $\left(81 \mathrm{~kJ} \mathrm{~mol}^{-1}\right)$. This difference made sugar production favorable in the GVL solvent system. Their conclusion was that reactions at lower temperatures were favorable for deconstructing biomass in the GVL-water solvent system to produce $C_{5}$ and $C_{6}$ sugars without their further conversion to furanic or degradation products. ${ }^{[5,15,191]}$ However, the mechanisms behind these phenomena are not yet well understood. A contributing factor could be the dynamic solvent ef-

\begin{tabular}{|c|c|c|c|c|c|c|c|}
\hline Feedstock & $\begin{array}{l}\text { Concentration } \\
{[\%]}\end{array}$ & Solvent & Catalyst & $\begin{array}{l}\text { Selectivity } \\
{[\%]}\end{array}$ & $\begin{array}{l}\text { Conversion } \\
{[\%]}\end{array}$ & $\begin{array}{l}\text { Yield } \\
{[\%]}\end{array}$ & Ref. \\
\hline \multirow[t]{15}{*}{ fructose } & 9 & water & $\mathrm{HCl}$ & 64 & 92 & 58 & [89] \\
\hline & 30 & water & FeVOP $[\mathrm{b}]$ & 84 & 71 & 60 & [90] \\
\hline & 11 & water & / & 57 & 89 & 51 & [89] \\
\hline & 8 & DMSO & / & 72 & 100 & 72 & [94] \\
\hline & 5 & DMSO & $\mathrm{NH}_{4} \mathrm{Cl}$ & 100 & 100 & 100 & [95] \\
\hline & 10 & DMA & $\mathrm{NaBr}, \mathrm{H}_{2} \mathrm{SO}_{4}$ & / & / & 93 & [93] \\
\hline & 9 & NMP & $\mathrm{FeCl}_{3} / \mathrm{Et}_{4} \mathrm{NCl}$ & 100 & 82 & 82 & [96] \\
\hline & 5 & ethyl acetate & $\mathrm{NH}_{4} \mathrm{Cl}$ & / & 100 & 58 & [95] \\
\hline & 5 & sulfolane & / & 100 & 100 & 100 & [95] \\
\hline & 40 & {$[\mathrm{SBMIm}]\left[\mathrm{HSO}_{4}\right]^{[\mathrm{c}]}$} & / & 94 & 98 & 92 & [97] \\
\hline & 18.8 & GVL & $\mathrm{H}_{2} \mathrm{SO}_{4}$ & / & / & 67 & [98] \\
\hline & 18.8 & acetone & $\mathrm{H}_{2} \mathrm{SO}_{4}$ & / & / & 65 & [98] \\
\hline & 18.8 & THF & $\mathrm{H}_{2} \mathrm{SO}_{4}$ & / & / & 75 & [98] \\
\hline & 18.8 & $\mathrm{MeCN}$ & $\mathrm{H}_{2} \mathrm{SO}_{4}$ & / & / & 70 & [98] \\
\hline & 23 & water (MIBK) & $\mathrm{Ag}_{3} \mathrm{PW}_{12} \mathrm{O}_{4}$ & 94 & 83 & 78 & [99] \\
\hline \multirow[t]{9}{*}{ glucose } & 9 & water & 1 & 51 & 21 & 10 & [92] \\
\hline & 8 & water & $\mathrm{DyCl}_{3}$ & 40 & 30 & 12 & [91] \\
\hline & 9 & water & $\mathrm{TiO}_{2}$ & 71 & 39 & 27 & [92] \\
\hline & 10 & $\mathrm{DMA} / \mathrm{LiBr}$ & $\mathrm{CrCl}_{3}$ & / & / & 80 & [93] \\
\hline & 9 & DMSO & $\mathrm{SnCl}_{4}$ & 45 & 96 & 44 & [100] \\
\hline & 8 & {$[\mathrm{BM} I m] \mathrm{Cl}$} & $\mathrm{NHC} / \mathrm{CrCl}_{3}$ & / & / & 81 & [101] \\
\hline & 23 & water (MIBK) & $\mathrm{Ag}_{3} \mathrm{PW}_{12} \mathrm{O}_{4}$ & 85 & 90 & 76 & [99] \\
\hline & 10 & water (THF) & $\mathrm{Sn}-\beta / \mathrm{HC}^{[\mathrm{d}]}$ & 72 & 79 & 57 & [102] \\
\hline & 6 & water (2-butanol) & $N A-P^{[e]}$ & 83 & 70 & 58 & [103] \\
\hline \multirow[t]{4}{*}{ xylose } & 10 & water & $\mathrm{HCl}$ & / & / & 30 & [105] \\
\hline & 5 & water (SBP) & $\mathrm{HCl}$ & 82 & 92 & 71 & [9] \\
\hline & 10 & water (MIBK) & $\mathrm{HCl}$ & / & / & 85 & [105] \\
\hline & 9.1 & DMSO & $\mathrm{MCM}-41-\mathrm{SO}_{3} \mathrm{H}^{[f]}$ & 90 & 77 & 69 & [106] \\
\hline
\end{tabular}

[a] Only reports with feedstock concentrations over $5 \%$ were selected for comparison. [b] $\left[\mathrm{Fe}\left(\mathrm{H}_{2} \mathrm{O}\right)\right] \cdot 2 \mathrm{VO}_{0.8} \mathrm{PO}_{4}+2.25 \mathrm{H}_{2} \mathrm{O}$. [c] 1-(4-Sulfonic acid) butyl-3methylimidazlium. [d] Sn-beta zeolite/ $\mathrm{HCl}$. [e] Hydrated niobium pentoxide. [f] Silica-based sulfonic acid. 
(a)

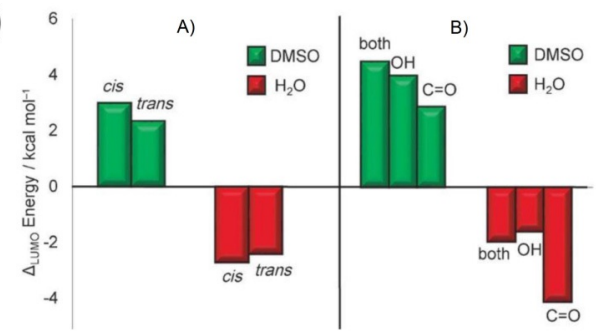

(b)

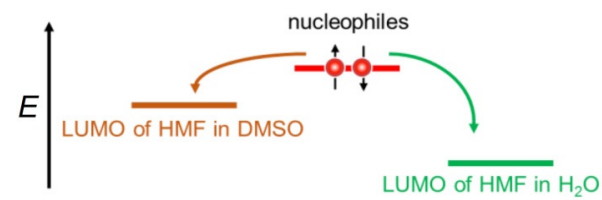

Figure 12. (a) Change in the LUMO energy of isolated HMF in water and DMSO solvents relative to gas-phase HMF: a) whole molecule system and b) individual functional group interactions and (b) orbital diagram for HMF condensation in water and DMSO through a nucleophilic attack mechanism. Part (a) was taken with permission from Tsilomelekis et al. ${ }^{[128]}$

fects discussed earlier. The reduced contribution of sugarsugar and sugar-furan condensation reactions in organic solvent systems due longer-lived hydrogen bonding between solvent or solute could contribute to stabilizing these products (Table 8). ${ }^{[131]}$

In summary, the effects of organic solvents on chemical thermodynamics are mostly proposed by assumption and/or calculated by computational modeling. Most of the modeling results indicated that organic solvents affect thermodynamics through the interaction of solvent molecules with the reactants, transition state, catalysts, and products. The stabilization or destabilization of the reactants, catalysts, and transition state will affect the activation energy of the reaction. In particular, using models it was found that solvents can affect functional groups in different ways. In some cases, generalizing the effect on specific functional groups could allow the development of semi-predictive models that do not require the simula- tion of complete molecular systems, which could be an interesting area of future research.

Furthermore, although we separated solvent effects on different reaction moieties, in practice these effects often act in concert and can even be correlated. As the transition state tends to resemble either the reactants or the products, any change in their free energy will likely occur in concert. In some cases, the argument can be made that one effect will take over. Notably, Mellmer et al. argue that a polar aprotic solvent can destabilize the acidic proton (catalyst) more than the significantly larger transition state, which leads to a decrease in the free energy of activation. ${ }^{[130]}$ However, as a general rule, it is important to consider the overall effects of the solvent on all the elements of the reaction.

\section{Processing Challenges for Organic Solvents}

Although organic solvents have demonstrated remarkable properties for improving the yields and selectivities of platform molecules produced from lignocellulosic biomass, there are multiple challenges associated with their use in an industrial biorefinery. Below, we discuss some of the issues that should be considered when selecting an organic solvent, which are summarized in Figure 13.

\subsection{Cost and recyclability}

Organic solvents have been widely used in the pharmaceutical industry as reaction media and refining solvents. Their loss and recovery have contributed significantly to the high price of medicine and cosmetic products. In comparison to pharmaceuticals, biomass-derived platform chemicals tend to have a considerably lower unit value, which compounds the issue of costs associated with solvents. One way to reduce these costs is to increase the biomass processing capacity per unit volume of solvent. Typically, this will reduce capital and operating costs as well as reduce solvent replacement and recycling costs. This was illustrated in the case of GVL use for producing

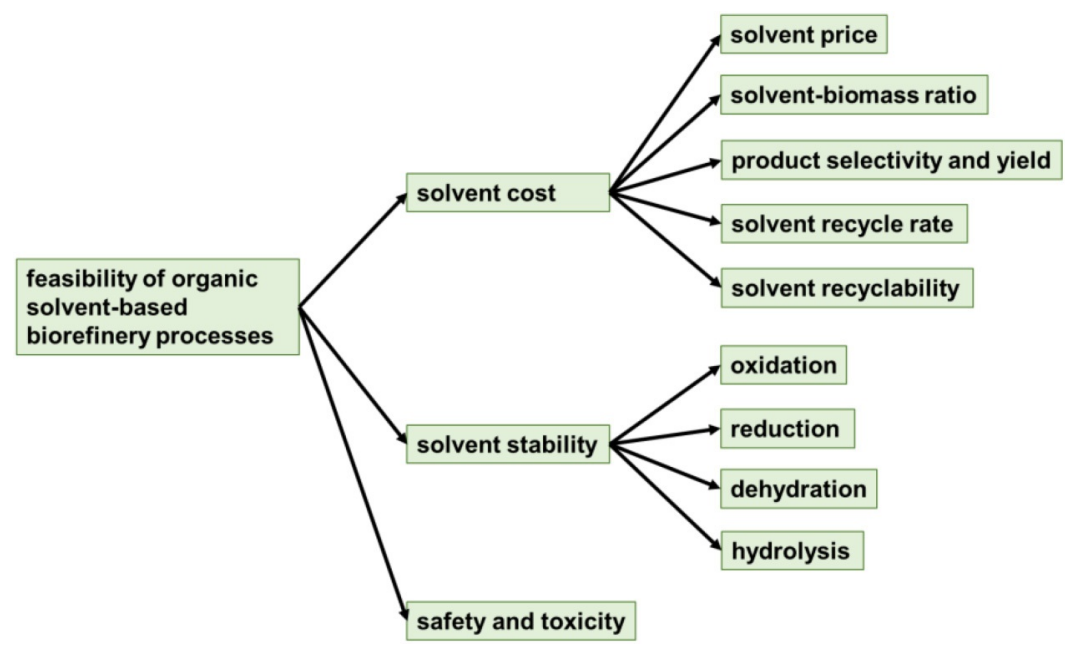

Figure 13. Factors affecting the feasibility of organic solvent-based biorefinery processes. 


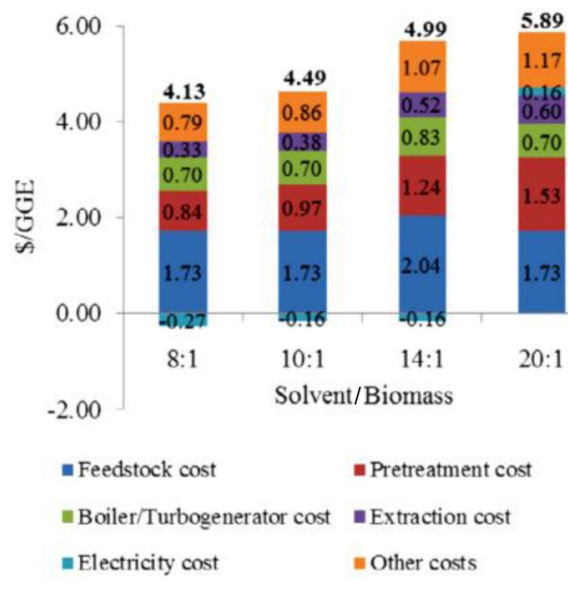

Figure 14. Economic impact of the GVL/biomass ratio on the MESP of ethanol. Taken with permission from Han et al. ${ }^{[239]}$

sugars and ethanol from biomass, where the final ethanol price depended highly on the solvent-to-biomass ratio (Figure 14). ${ }^{[239]}$ Furthermore, because the solvent cost is often similar or higher than the cost of the platform molecule being produced, the recovery ratio should be nearly $100 \%$. Since distillation is a common recovery method, the solvent's boiling point is often directly related to its recyclability. Table 10 lists common solvents used in biomass conversion and their boiling points.

\begin{tabular}{|lcc|}
\hline \multicolumn{3}{|l|}{ Table 10. Boiling points and vaporization enthalpies of common solvents } \\
used in biomass conversion. ${ }^{[a]}$
\end{tabular}

[a] Data was taken from the National Institute of Standards and Technology Webbook: http://webbook.nist.gov/. [b] Thermal stability. [c] ILs have extremely low vapor pressure below their decomposition temperature.

Low-boiling-point solvents, such as methanol, ethanol, acetone, and THF, seem to be the most promising organic solvents for biomass conversion owing to their low cost and easy recyclability. Biomass pretreated in these solvents show significant enhancement in enzymatic digestibility. Dehydration of glucose into HMF and dehydration of xylose into furfural in these solvents also show enhanced yields. However, the low boiling points also cause significant increases in vapor pres- sure, increasing reactor costs, and often require cooling systems during recovery.

High-boiling-point solvents such as DMSO, DMF, and GVL have arguably demonstrated even more interesting results in biomass conversion into sugars and chemicals. These solvents have relatively low vapor pressures, which can reduce reactor costs. However, the recyclability of these solvents is a major issue. Direct distillation or liquid-liquid extraction is possible, yet energy intensive. Besides, high-boiling-point solvents applied in biomass conversion are usually more expensive than common low-boiling-point solvents. However, recent work showing that solvents such as GVL could be recycled using high pressure $\mathrm{CO}_{2}$ with less than 1:1 $\mathrm{CO}_{2}$-to-solvent ratios could facilitate the implementation of these solvents. ${ }^{[15,239]}$

In addition to the solvents' boiling points, vaporization enthalpy is another major factor to be considered, especially as it is directly related to the energy needed to vaporize the solvent. Notably, organic solvents usually have considerably lower vaporization enthalpies than water (Table 10). Small alcohols such as methanol and ethanol have a higher vaporization enthalpy than other solvents due to their ability to form $\mathrm{H}$ bonds. In comparison, acetone and THF or higher boiling solvents such as MIBK and GVL require less energy during separation. These multiple factors, coupled to the necessity of recovering almost all solvent to enable an economical process, underline the importance of suitable process modeling and heat integration when evaluating solvent use in biomass conversion.

To decrease the economic and environmental cost of solvents, the organic solvents can be produced from biomass itself. Furthermore, if the solvent and the product are the same, it is not necessary to completely recover all the solvent as the product and the solvent are the same. For example, GVL, when used as a solvent, has shown good benefits for the production of HMF, furfural, and levulinic acid, which are precursors for making GVL. ${ }^{[98,109,240,241]}$ Residual GVL in water could be recovered in combination with newly generated GVL or be directly used for the next cycle without separation. In ethanol pretreatment, ethanol might not have to be completely recovered as residual ethanol could be brought to the downstream fermentation step where ethanol is the product. Even if the solvent and product are not the same, producing the solvent from biomass itself can have sustainability and economic advantages because the solvent make-up can be integrated into the biorefinery. For this reason, several groups have explored the possibility of making more sustainable biomass-derived ILs. $^{\text {[70,242] }}$

Nonvolatile ILs show unique performances in biomass pretreatment, lignin depolymerization, and dehydration of sugars, but the strategy to recover costly IL is not yet well established. At present, ILs are too expensive for biomass conversion. KleinMarcuschamer and co-workers established a technoeconomic model to evaluate the feasibility of employing IL as solvent for biomass pretreatment. ${ }^{[243]}$ They conducted a sensitivity analysis on the principal factors affecting costs of IL pretreatment and found that the IL cost is the major factor affecting the minimum ethanol selling price (MSEP). When the price of IL was 
(a)

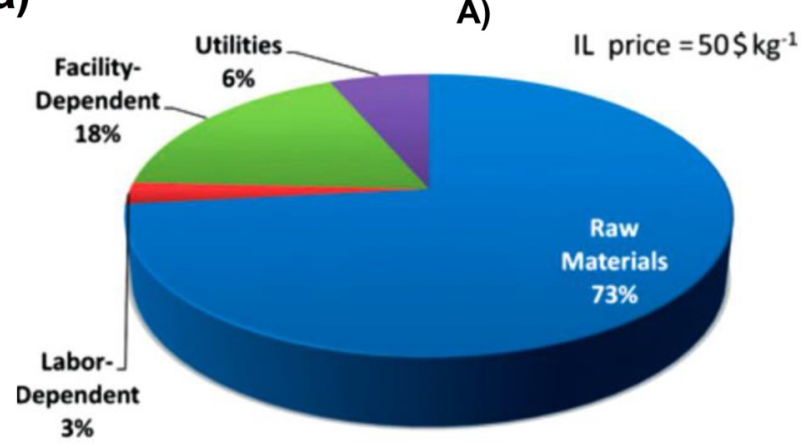

IL price $=2.5 \$ \mathrm{~kg}^{-1}$

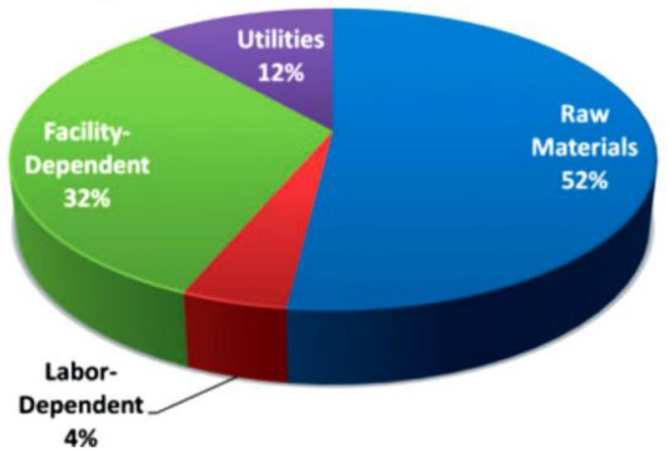

(b)
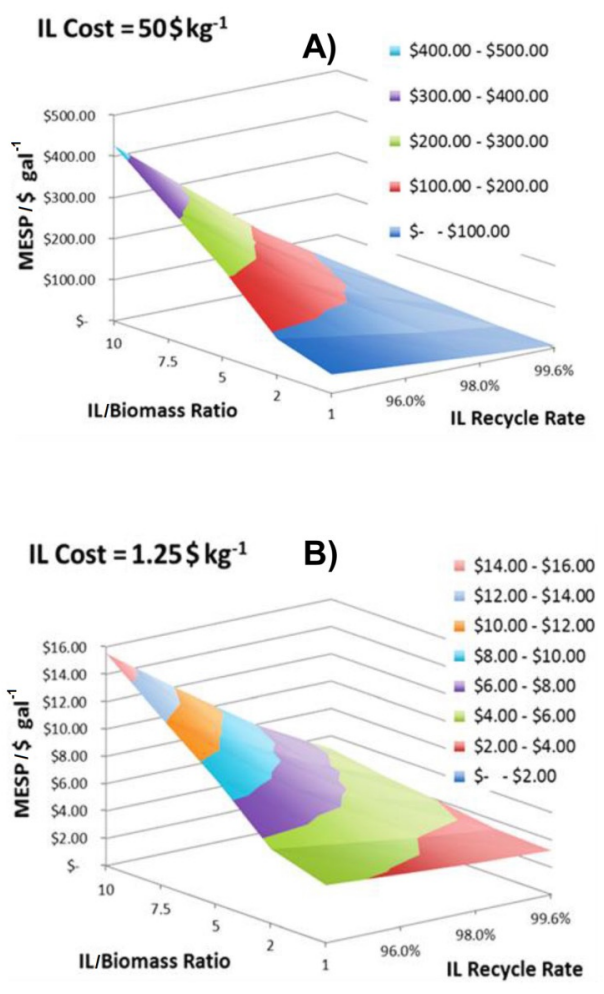

Figure 15. (a) Distribution of the annual operating cost of the modeled biorefinery at two IL purchase prices, 50 (A) and $2.5 \$ \mathrm{~kg}^{-1}$ (B), for a process with a IL/ biomass ratio of 1 and a recycle rate of $99.6 \%$; $^{[243]}(\mathrm{b})$ minimum ethanol selling price at two IL purchase prices, $50(\mathrm{~A})$ and $1.25 \$ \mathrm{~kg}{ }^{-1}(\mathrm{~B})$, for various IL-biomass ratios and IL recycle rates. Taken with permission from Klein-Marcuschamer et al. ${ }^{[243]}$

$50 \$ \mathrm{~kg}^{-1}$, the cost of material accounted for $73 \%$ of ethanol cost, versus $52 \%$ for ILs with a price of $2.5 \$ \mathrm{~kg}^{-1}$ (Figure $15 \mathrm{a}) .{ }^{[243]}$ Therefore, the amount of non-recycled IL solvent seems to be the main cost driver, with most raw materials costs linked to purchasing solvent to make up for the loss of solvent ILs.

Geroge and co-workers conducted a similar analysis on the IL pretreatment process (Figure 15b). ${ }^{[24]}$ They also found that the price of IL was the major factor limiting its use. At high IL prices (e.g., $50 \$ \mathrm{~kg}^{-1}$ ), MESP was over $6 \$$ gallon $^{-1}$ even at a very high IL recycle rate of $99.6 \%$, and a $1: 1 \mathrm{IL} /$ biomass ratio, versus $3.22 \$$ gallon $^{-1}$ for an IL costing $1.25 \$ \mathrm{~kg}^{-1}$. This suggested that the price of a particular IL should be a major criterion for screening these solvents for biomass conversion. Based on this model, a cost estimate can be made for other organic solvents involved in biomass conversion processes by substituting the IL with other organic solvents. At recycle rates of $99.6 \%$, solvent ratios of 10:1 will lead to a range of prices from 5 to $3 \$$ gallon $^{-1}$. Only solvent ratios [ratio of solvent volume $(\mathrm{mL})$ to weight of biomass $(\mathrm{g})$ ] lower than 4 can lead to MESPs lower than $3.5 \$$ gallon $^{-1}$. For biomass pretreatment, if $25 \%$ of the cost is saved by not using enzymes, MESPs of 2.25-4.00 $\$$ gallon $^{-1}$ can be reached for non-enzymatic biomass conversion processes. Recently, a GVL-based non-enzymatic saccharification process was reported, which resulted in a selling price of $4.87 \$$ gallon $^{-1}$ of gasoline equivalent (a MESP of $3.23 \$$ gallon $\left.^{-1}\right){ }^{[15]}$ This cost was similar to the standard ethanol cost resulting from dilute acid pretreatment and no solvent usage published by the National Renewable Energy Laboratory (NREL), which was 5.13 \$ gallon $^{-1}$ of gasoline equivalent (a MESP of $3.4 \$$ gallon $^{-1}$ ). ${ }^{[245]}$ This demonstrates that if enzyme costs are removed there is more flexibility in adjusting solvent loadings and recycling ratios.

These considerations can also provide some indications for producing other molecules from biomass. For example, high yields of HMF are often obtained at low concentrations of glucose or fructose ${ }^{[2]}$ but these high solvent/biomass ratios could cause similar issues in terms of solvent recovery or replacement costs. HMF yields of $35-50 \%$ could be obtained with real biomass at a IL/biomass ratio of 20:1. ${ }^{[246,247]}$ Based on the IL pricing estimates discussed above (on the basis of a sugar yield of $80 \%$ ), we can make a quick estimate of the solvent costs associated with HMF produced from biomass using IL as a solvent, assuming that there the cost will vary proportionally with the change of solvent ratio and yield. A process with $80 \%$ HMF yield at a 10:1 IL/biomass ratio leads to a selling price of $5 \$$ gallon $^{-1}$. To obtain the same amount of HMF, a process with $40 \% \mathrm{HMF}$ yield at 20: $1 \mathrm{IL} /$ biomass ratio needs to be run four times with identical reaction systems, increasing the HMF selling price four times to $20 \$$ gallon $^{-1}\left(\sim 4 \$ \mathrm{~kg}^{-1}\right.$ or $\sim 4000 \$$ ton $^{-1}$ ). This cost is considerably higher than those of common solvent $\left(1.25-2.5 \$ \mathrm{~kg}^{-1}\right)$. Either decreasing solvent ratios to $10: 1$ or increasing yields to above $80 \%$ could decrease the HMF selling price by half to roughly $2 \$ \mathrm{~kg}^{-1}$. However, increasing feedstock concentration generally leads to lower selectivities due to the increased formation of humins. In 
summary, although furans are higher-value compounds the issue of solvent cost is still likely to be significant because of the lower selectivity associated with their production.

\subsection{Stability (decomposed or reacted)}

Generally, organic solvents contain some reactive functional groups, which will often lead to side reactions with lignocellulosic biomass and cause some loss of solvent. In ethanol organosolv pretreatment, ethanol can react with $\alpha$-hydroxyl groups to increase the solubility of lignin and prevent its condensation, which is beneficial but results in the loss of ethanol. ${ }^{[37-39]}$ In acetic-acid pretreatment, acetic acid reacted with the hydroxyl groups of cellulose to form cellulose acetate, blocking enzyme complexation to the surface of cellulose and leading to low glucose yields. ${ }^{[47,248]}$ Treating acetic-acid-pretreated material with dilute alkali could remove the acetyl groups and significantly improve the yield of glucose. Similar reactions happened in formic acid pretreatment where formyl groups were grafted on the cellulose surface. ${ }^{[48]}$

When organic solvents are applied in the catalytic conversion of biomass-derived oxygenates, the stability of organic solvents is even more critical. Using catalysts and high pressures of $\mathrm{H}_{2}$ or $\mathrm{O}_{2}$, these solvents can undergo dehydration, hydrogenolysis, reduction, and oxidation reactions. Ether and ester solvents such as GVL and THF have performed well in biomass conversion, but they can be hydrolyzed in the presence of significant amounts of water and acid or base catalysts. Stability of GVL has been studied at $470 \mathrm{~K}$ for $100 \mathrm{~h}$ in the presence of acid, and it was found that $90 \%$ of the original GVL remained while rapidly forming an equilibrium concentration of $10 \%$ pentenoic acid. ${ }^{[15]}$ However, this equilibrium concentration of acid did not affect the biomass conversion yields. Biomass-derived furanic compounds have been widely investigated for producing hydrocarbon fuels through ring opening and hydrodeoxygenation. When using THF as solvent for catalytic hydrodeoxygenation, the reaction conditions were tuned to avoid the ring opening of THF. ${ }^{[249]}$ Besides, ether compounds such as THF and dioxane can be oxidized into peroxides in air, which require special attention due to their explosive nature. ${ }^{[250]}$ Similarly, alcohol solvents can also be dehydrated into olefins at temperatures above $160^{\circ} \mathrm{C}$ in the presence of acid catalysts. ${ }^{[251,252]}$ Some ILs were also found to be unstable. The $\mathrm{IL}$ anion $\left[\mathrm{MeOSO}_{3}\right]^{-}$was found to partially hydrolyze to form $\left[\mathrm{HSO}_{4}\right]^{-}$due to the presence of water. ${ }^{[71]}$ Similarly, dealkylation reactions were observed for 1-ethyl-3-methylimidazolium acetate $\left(\left[\mathrm{C}_{2} \mathrm{C}_{1} \mathrm{im}\right][\mathrm{OAC}]\right)$ at temperatures as low as $120^{\circ} \mathrm{C} .{ }^{[253]}$ Therefore, long-term stability studies are essential when studying a given solvent system for industrial use, but data is often limited especially for novel solvent systems.

\subsection{Safety and toxicity (biodegradability, compatibility with organisms)}

Several environmental health and safety issues need to be considered when using organic solvents. For example, low-boiling solvents tend to vaporize quickly and generally emit more or less unpleasant odors. More importantly, organic solvents can have negative effects on the human metabolism especially in cases of long-term exposure. Systematic long-term health effects have not been studied for most of the solvents discussed here, but we list a few of the effects of more well-known biomass conversion solvents. Methanol is harmful to vision and continuous exposure can cause blindness. ${ }^{[254,255]}$ Furan-based products were claimed to be carcinogenic because they have been linked to the formation of tumors after their continuous feeding to mice. ${ }^{[256,257]}$ DMSO was demonstrated to induce retinal apoptosis in vivo at low concentrations $(5 \mu \mathrm{L}$ intravitreally dosed DMSO in rat from a stock concentration of 1, 2, 4, and $8 \% v / v){ }^{[230]}$ These findings indicate that negative effects of organic solvents on the human body are likely and not well studied, especially for some of the less common molecules discussed here. For this reason, strict safety measures are likely to be required in an industrial setting. These measures should be taken into account in economic analyses because they can increase operating costs compared to benign solvents such as water.

\section{Conclusions and Outlook}

Organic solvents have been shown to have significant effects on reaction rates and product selectivity in biomass conversion processes. Increasing rates and selectivity are essential for maximizing product yield and improving conversion efficiencytwo major barriers preventing renewable resources from being economically competitive with petroleum products. For these reasons, solvents could play a key role in future biomass conversion processes. In this Review, we have discussed and analyzed the different types of solvent effects that change reaction rates, selectivities and overall yields in the presence of organic solvents. We have identified and discussed two broad categories of solvent effects: (1) those affecting the solubilities of biomass fractions (e.g., lignin, hemicellulose, and cellulose) and biomass-derived molecules (sugars, furans, etc.), and (2) those affecting chemical reaction thermodynamics. Within effects on reaction thermodynamics, we have described solvent effects on the free energy of the different molecules and complexes involved in the reaction including the catalyst, reactants, transition state, and products.

Due to the complexity of biomass conversion reactions, many of these effects impact multiple conversion steps. However, categorizing these effects could help guide solvent research and development by targeting a specific effect. For example, an organic solvent, including an ionic liquid (IL), could be modified to affect a given catalyst, reactant, or transition state more strongly and accelerate a given reaction step. Such a reaction step could be accelerated by selectively destabilizing reactants or catalysts or by selectively stabilizing the transition state. Another approach would be to change the product distribution by modifying a solvent to selectively stabilize or destabilize a given product. Modern computational tools could be especially useful in developing these targeted solvent-engineering approaches. 
Most of the effects discussed in this Review have been static effects, which represent the majority of solvent effects explored in the context of biomass conversion. However, as we described in our general discussion on solvent effects, prior research on different reactions has identified dynamic effects as a major factor in several chemical systems, especially those using high viscosity solvents. Several biomass conversion reactions are likely to occur in the presence of high viscosities including the initial depolymerization reactions of cellulose, hemicellulose, and lignin or the high solids processing of biomass and sugar solutions. These reaction systems are likely to be at least partially governed by dynamic solvent effects. Given the relative lack of knowledge in the area of dynamic solvent effects in biomass conversion, this represents an important opportunity for characterizing and potentially taking advantage of this category of effects when studying and engineering new solvent systems.

Finally, as these promising solvents are increasingly considered for implementation in industrial biorefineries, our Review shows that factors such as high recyclability and low solventto-biomass ratios are essential for developing competitive processes. Solvent stability is also essential, and long-term stability data are often scarce and should be increasingly considered if a given solvent is to be proposed for biomass processing. Furthermore, considerations such as the sustainability or toxicity of a solvent can have important environmental and health implications, which could hinder a solvent's implementation on industrial scale. In summary, many opportunities exist in the understanding and development of specific solvent effects. However, basic research must be accompanied by the careful consideration and study of the practical aspects of large-scale solvent use.

\section{Acknowledgements}

The authors acknowledge financial support from the Swiss Competence Center for Energy Research: Biomass for Swiss Energy Future (SCCER-BIOSWEET) funded by the Swiss Commission for Technology and Innovation through grant KTI.2014.0116.

Keywords: biomass $\cdot$ biorefineries $\cdot$ solubility $\cdot$ solvent effects thermodynamics

[1] V. Balan, Int. Sch. Res. Not. 2014, 2014, 1-31.

[2] R.-J. van Putten, J. C. van der Waal, E. de Jong, C. B. Rasrendra, H. J. Heeres, J. G. de Vries, Chem. Rev. 2013, 113, 1499-1597.

[3] J. S. Luterbacher, D. M. Alonso, J. A. Dumesic, Green Chem. 2014, 16, $4816-4838$.

[4] J. Long, Q. Zhang, T. Wang, X. Zhang, Y. Xu, L. Ma, Bioresour. Technol. 2014, 154, 10-17.

[5] M. A. Mellmer, D. M. Alonso, J. S. Luterbacher, J. M. R. Gallo, J. A. Dumesic, Green Chem. 2014, 16, 4659-4662.

[6] C. B. Rasrendra, J. N. M. Soetedjo, I. G. B. N. Makertihartha, S. Adisasmito, H. J. Heeres, Top. Catal. 2012, 55, 543-549.

[7] Y. Wang, H. Wang, H. Lin, Y. Zheng, J. Zhao, A. Pelletier, K. Li, Biomass Bioenergy 2013, 59, 158-167.

[8] P. Weerachanchai, S. K. Kwak, J.-M. Lee, Bioresour. Technol. 2014, 170, $160-166$.
[9] E. I. Gürbüz, S. G. Wettstein, J. A. Dumesic, ChemSusChem 2012, 5 , $383-387$.

[10] Y. J. Pagán-Torres, T. Wang, J. M. R. Gallo, B. H. Shanks, J. A. Dumesic, ACS Catal. 2012, 2, 930-934.

[11] Y. Román-Leshkov, C. J. Barrett, Z. Y. Liu, J. A. Dumesic, Nature 2007, 447, $982-985$.

[12] S. G. Wettstein, D. M. Alonso, Y. Chong, J. A. Dumesic, Energy Environ. Sci. 2012, 5, 8199-8203.

[13] Y. Román-Leshkov, J. N. Chheda, J.A. Dumesic, Science 2006, 312, $1933-1937$.

[14] H. Zhao, J.E. Holladay, H. Brown, Z. C. Zhang, Science 2007, 316, $1597-1600$.

[15] J. S. Luterbacher, J. M. Rand, D. M. Alonso, J. Han, J. T. Youngquist, C. T. Maravelias, B. F. Pfleger, J. A. Dumesic, Science 2014, 343, 277-280.

[16] J. B. Binder, R. T. Raines, Proc. Natl. Acad. Sci. USA 2010, 107, $4516-$ 4521.

[17] S. C. Bhatia in Advanced Renewable Energy Systems (Ed.: S. C. Bhatia), Woodhead Publishing India, 2014, pp. 403-425.

[18] C. Chatterjee, F. Pong, A. Sen, Green Chem. 2015, 17, 40-71.

[19] J. A. Melero, J. Iglesias, A. Garcia, Energy Environ. Sci. 2012, 5, 7393 7420.

[20] J. C. Serrano-Ruiz, J. A. Dumesic, Energy Environ. Sci. 2011, 4, 83-99.

[21] H. Tadesse, R. Luque, Energy Environ. Sci. 2011, 4, 3913-3929.

[22] A. R. C. Morais, A.M. da Costa Lopes, R. Bogel-tukasik, Chem. Rev. 2015, 115, 3-27.

[23] X. Zhao, L. Zhang, D. Liu, Biofuels Bioprod. Biorefin. 2012, 6, 465-482.

[24] S. G. Wettstein, D. M. Alonso, E. I. Gürbüz, J. A. Dumesic, Curr. Opin. Chem. Eng. 2012, 1, 218-224.

[25] L. Shuai, Q. Yang, J. Y. Zhu, F. C. Lu, P. J. Weimer, J. Ralph, X. J. Pan, Bioresour. Technol. 2010, 101, 3106-3114.

[26] D. Xin, Z. Yang, F. Liu, X. Xu, J. Zhang, Bioresour. Technol. 2015, 175, $529-536$.

[27] C. Li, B. Knierim, C. Manisseri, R. Arora, H. V. Scheller, M. Auer, K. P. Vogel, B. A. Simmons, S. Singh, Bioresour. Technol. 2010, 101, 4900 4906.

[28] A. M. J. Kootstra, H. H. Beeftink, E. L. Scott, J. P. M. Sanders, Biochem Eng. J. 2009, 46, 126-131.

[29] T.-C. Hsu, G.-L. Guo, W.-H. Chen, W.-S. Hwang, Bioresour. Technol. 2010 101, 4907-4913.

[30] L. Yan, L. Zhang, B. Yang, Biotechnol. Biofuels 2014, 7, 76.

[31] O. Akpinar, O. Levent, S. Sabanci, R. S. Uysal, B. Sapci, BioResources 2011, 6, 4103-4116.

[32] X. Zhao, K. Cheng, D. Liu, Appl. Microbiol. Biotechnol. 2009, 82, 815 827.

[33] M. A. Gilarranz, F. Rodríguez, A. Santos, M. Oliet, F. García-Ochoa, J. Tijero, Ind. Eng. Chem. Res. 1999, 38, 3324-3332.

[34] E. Minami, S. Saka, J. Wood Sci. 2003, 49, $73-78$.

[35] L. Paszner, P.-C. Chang, (Thermoform Bau Forschung), US4409032A, 1983.

[36] P.-C. Chang, L. Paszner, (Thermoform Bau Forschung), CA1131415 A1, 1982.

[37] X. Pan, D. Xie, R. W. Yu, D. Lam, J. N. Saddler, Ind. Eng. Chem. Res. 2007, 46, 2609-2617.

[38] X. Pan, N. Gilkes, J. Kadla, K. Pye, S. Saka, D. Gregg, K. Ehara, D. Xie, D. Lam, J. Saddler, Biotechnol. Bioeng. 2006, 94, 851-861.

[39] Z. Li, Z. Jiang, B. Fei, X. Pan, Z. Cai, X. 'e Liu, Y. Yu, BioResources 2012, 7, $3452-3462$.

[40] C. Arato, E. K. Pye, G. Gjennestad, Appl. Biochem. Biotechnol. 2005, 123, $0871-0882$.

[41] X. Pan, C. Arato, N. Gilkes, D. Gregg, W. Mabee, K. Pye, Z. Xiao, X Zhang, J. Saddler, Biotechnol. Bioeng. 2005, 90, 473-481.

[42] C. Hongzhang, L. Liying, Bioresour. Technol. 2007, 98, 666-676.

[43] E. Araque, C. Parra, J. Freer, D. Contreras, J. Rodríguez, R. Mendonça, J. Baeza, Enzyme Microb. Technol. 2008, 43, 214-219.

[44] I. Hasegawa, K. Tabata, O. Okuma, K. Mae, Energy Fuels 2004, 18, $755-$ 760.

[45] X.-B. Zhao, L. Wang, D.-H. Liu, J. Chem. Technol. Biotechnol. 2008, 83, 950-956.

[46] S. Duncan, Q. Jing, A. Katona, R. J. Kazlauskas, J. Schilling, U. Tschirner, W. W. AIDajani, Appl. Biochem. Biotechnol. 2010, 160, 1637-1652.

[47] X. Pan, Y. Sano, Bioresour. Technol. 2005, 96, 1256-1263. 
[48] J. Snelders, E. Dornez, B. Benjelloun-Mlayah, W. J. J. Huijgen, P. J. de Wild, R. J. A. Gosselink, J. Gerritsma, C. M. Courtin, Bioresour. Technol. 2014, 156, 275-282.

[49] X. Zhao, Y. Morikawa, F. Qi, J. Zeng, D. Liu, Bioresour. Technol. 2014, $151,128-136$.

[50] X. Pan, N. Gilkes, J. N. Saddler, Holzforschung 2006, 60, 398-401.

[51] T. Y. Nguyen, C. M. Cai, R. Kumar, C. E. Wyman, ChemSusChem 2015, 8, $1716-1725$.

[52] D. Fu, G. Mazza, Y. Tamaki, J. Agric. Food Chem. 2010, 58, 2915-2922.

[53] Q. Li, X. Jiang, Y. He, L. Li, M. Xian, J. Yang, Appl. Microbiol. Biotechnol. 2010, 87, 117-126.

[54] H. Zhao, G. A. Baker, J. V. Cowins, Biotechnol. Prog. 2010, 26, 127-133.

[55] S. H. Lee, T. V. Doherty, R. J. Linhardt, J. S. Dordick, Biotechnol. Bioeng. 2009, 102, 1368- 1376.

[56] J. F. Harris, A. J. Baker, A. H. Conner, T. W. Jeffries, J. L. Minor, R. C. Pettersen, R. W. Scott, E. L. Springer, T. H. Wegner, J. I. Zerbe, Two-Stage, Dilute Sulfuric Acid Hydrolysis of Wood: An Investigation of Fundamentals, 1985.

[57] P. Lenihan, A. Orozco, E. O'Neill, M. N. M. Ahmad, D. W. Rooney, G. M. Walker, Chem. Eng. J. 2010, 156, 395-403.

[58] I. A. Malester, M. Green, G. Shelef, Ind. Eng. Chem. Res. 1992, 31, 1998 2003.

[59] R. D. Fagan, H. E. Grethlein, A. O. Converse, A. Porteous, Environ. Sci. Technol. 1971, 5, 545-547.

[60] J. F. Saeman, Ind. Eng. Chem. 1945, 37, 43-52.

[61] J.-P. Franzidis, A. Porteous, J. Anderson, Conserv. Recycl. 1982, 5, 215 225.

[62] Y. P. Wijaya, R. D. D. Putra, V. T. Widyaya, J.-M. Ha, D. J. Suh, C. S. Kim, Bioresour. Technol. 2014, 164, $221-231$.

[63] F. Bergius, Ind. Eng. Chem. 1937, 29, 247-253.

[64] Z.-S. Liu, X.-L. Wu, K. Kida, Y.-Q. Tang, Bioresour. Technol. 2012, 119, $224-233$.

[65] S. T. Moe, K. K. Janga, T. Hertzberg, M.-B. Hägg, K. Øyaas, N. Dyrset, Energy Procedia 2012, 20, 50-58.

[66] M. loelovich, ISRN Chem. Eng. 2012, 2012, 1-7.

[67] R. Erckel, R. Franz, R. Woernle, T. Riehm, (Hoechst AG), US4556431A, 1985.

[68] S. M. Selke, M. C. Hawley, H. Hardt, D. T. A. Lamport, G. Smith, J. Smith, Ind. Eng. Chem. Prod. Res. Dev. 1982, 21, 11-16.

[69] N. Sun, H. Liu, N. Sathitsuksanoh, V. Stavila, M. Sawant, A. Bonito, K. Tran, A. George, K. L. Sale, S. Singh, B. A. Simmons, B. M. Holmes, Biotechnol. Biofuels 2013, 6, 39.

[70] A. M. Socha, R. Parthasarathi, J. Shi, S. Pattathil, D. Whyte, M. Bergeron, A. George, K. Tran, V. Stavila, S. Venkatachalam, M. G. Hahn, B. A. Simmons, S. Singh, Proc. Natl. Acad. Sci. USA 2014, 111, E3587-E3595.

[71] A. Brandt, M. J. Ray, T. Q. To, D. J. Leak, R. J. Murphy, T. Welton, Green Chem. 2011, 13, 2489-2499.

[72] A. Brandt, J. P. Hallett, D. J. Leak, R. J. Murphy, T. Welton, Green Chem. 2010, 12, $672-679$

[73] J.-L. Wen, T.-Q. Yuan, S.-L. Sun, F. Xu, R.-C. Sun, Green Chem. 2014, 16, $181-190$.

[74] J.-M. Lavoie, W. Baré, M. Bilodeau, Bioresour. Technol. 2011, 102, 4917 4920.

[75] V. M. Roberts, V. Stein, T. Reiner, A. Lemonidou, X. Li, J. A. Lercher Chem. Eur. J. 2011, 17, 5939-5948.

[76] R. Beauchet, F. Monteil-Rivera, J. M. Lavoie, Bioresour. Technol. 2012 $121,328-334$.

[77] A. Toledano, L. Serrano, J. Labidi, J. Chem. Technol. Biotechnol. 2012 , $87,1593-1599$

[78] Wahyudiono, M. Sasaki, M. Goto, Chem. Eng. Process. 2008, 47, 16091619.

[79] J. S. Luterbacher, A. Azarpira, A. H. Motagamwala, F. Lu, J. Ralph, J. A. Dumesic, Energy Environ. Sci. 2015, 8, 2657-2663.

[80] K. Stärk, N. Taccardi, A. Bösmann, P. Wasserscheid, ChemSusChem 2010, 3, 719-723.

[81] J. R. Gasson, D. Forchheim, T. Sutter, U. Hornung, A. Kruse, T. Barth, Ind. Eng. Chem. Res. 2012, 51, 10595-10606.

[82] B. J. Cox, J. G. Ekerdt, Bioresour. Technol. 2012, 118, 584-588.

[83] J. E. Miller, L. Evans, A. Littlewolf, D. E. Trudell, Fuel 1999, 78, 1363 1366.
[84] S. Takami, K. Okuda, X. Man, M. Umetsu, S. Ohara, T. Adschiri, Ind. Eng. Chem. Res. 2012, 51, 4804-4808.

[85] X. Huang, T. I. Korányi, M. D. Boot, E. J. M. Hensen, ChemSusChem 2014, 7, 2276-2288

[86] S. Van den Bosch, W. Schutyser, S.-F. Koelewijn, T. Renders, C. M. Courtin, B. F. Sels, Chem. Commun. 2015, 51, 13158-13161.

[87] S. Van den Bosch, W. Schutyser, R. Vanholme, T. Driessen, S.-F. Koelewijn, T. Renders, B. D. Meester, W. J. J. Huijgen, W. Dehaen, C. M. Courtin, B. Lagrain, F. F. Sels, Energy Environ. Sci. 2015, 8, 1748-1763.

[88] W. Schutyser, S. Van den Bosch, T. Renders, T. De Boe, S.-F. Koelewijn, A Dewaele, T. Ennaert, O. Verkinderen, B. Goderis, C. M. Courtin, B. F. Sels, Green Chem. 2015, 17, 5035-5045.

[89] Y. Li, X. Lu, L. Yuan, X. Liu, Biomass Bioenergy 2009, 33, 1182-1187.

[90] C. Carlini, P. Patrono, A. M. R. Galletti, G. Sbrana, Appl. Catal. A 2004, $275,111-118$.

91] K. Seri, Y. Inoue, H. Ishida, Bull. Chem. Soc. Jpn. 2001, 74, 1145-1150.

[92] A. Chareonlimkun, V. Champreda, A. Shotipruk, N. Laosiripojana, Fuel 2010, 89, 2873-2880.

[93] J. B. Binder, R. T. Raines, J. Am. Chem. Soc. 2009, 131, 1979-1985

[94] H. Yan, Y. Yang, D. Tong, X. Xiang, C. Hu, Catal. Commun. 2009, 10, $1558-1563$.

[95] C. Aellig, I. Hermans, ChemSusChem 2012, 5, 1737-1742.

[96] X. Tong, M. Li, N. Yan, Y. Ma, P. J. Dyson, Y. Li, Catal. Today 2011, 175, $524-527$.

[97] F. Tao, H. Song, L. Chou, RSC Adv. 2011, 1, 672-676.

[98] L. Qi, Y. F. Mui, S. W. Lo, M. Y. Lui, G. R. Akien, I. T. Horváth, ACS Catal. 2014, 4, 1470-1477.

[99] C. Fan, H. Guan, H. Zhang, J. Wang, S. Wang, X. Wang, Biomass Bioenergy $2011,35,2659-2665$

[100] S. Hu, Z. Zhang, J. Song, Y. Zhou, B. Han, Green Chem. 2009, 11, $1746-$ 1749.

[101] G. Yong, Y. Zhang, J. Y. Ying, Angew. Chem. Int. Ed. 2008, 47, $9345-$ 9348; Angew. Chem. 2008, 120, 9485-9488.

[102] E. Nikolla, Y. Román-Leshkov, M. Moliner, M. E. Davis, ACS Catal. 2011, 1, 408-410.

[103] F. Yang, Q. Liu, X. Bai, Y. Du, Bioresour. Technol. 2011, 102, 3424-3429.

[104] D. F. Root, J. F. Saeman, J. F. Harris, W. K. Neill, For. Prod. J. 1959, 9, $158-165$.

[105] R. Weingarten, J. Cho, Wm. C. Conner Jr, G. W. Huber, Green Chem. 2010, 12, 1423-1429.

[106] A. S. Dias, M. Pillinger, A. A. Valente, J. Catal. 2005, 229, 414-423.

[107] W. Wang, H. Li, J. Ren, R. Sun, J. Zheng, G. Sun, S. Liu, Chin. J. Catal. 2014, 35, $741-747$.

[108] M. J. Campos Molina, R. Mariscal, M. Ojeda, M. López Granados, Bioresour. Technol. 2012, 126, $321-327$.

[109] J. A. Dumesic, D. M. Alonso, E. I. Gürbüz, S. G. Wettstein, US8399688 B2, 2013.

[110] F. Tao, H. Song, L. Chou, Can. J. Chem. 2011, 89, 83-87.

[111] K. L. Von Hebel, J.-P. Lange, (Shell Int. Research) WO2011141545A1, 2011.

[112] D. Knežević, W. van Swaaij, S. Kersten, Ind. Eng. Chem. Res. 2010, 49, $104-112$.

[113] J. Yamazaki, E. Minami, S. Saka, J. Wood Sci. 2006, 52, 527-532.

[114] I. J. Miller, S. K. Fellows, Fuel 1985, 64, 1246- 1250.

[115] T. Yamada, M. Aratani, S. Kubo, H. Ono, J. Wood Sci. 2007, 53, $487-$ 493.

[116] S.-P. Fan, S. Zakaria, C.-H. Chia, F. Jamaluddin, S. Nabihah, T.-K. Liew, F.L. Pua, Bioresour. Technol. 2011, 102, 3521-3526.

[117] Z. Liu, F. Zhan, Energy Convers. Manage. 2008, 49, 3498-3504.

[118] S. Cheng, I. D'cruz, M. Wang, M. Leitch, C. Xu, Energy Fuels 2010, 24 4659-4667.

[119] N. P. Vasilakos, D. M. Austgen, Ind. Eng. Chem. Process Des. Dev. 1985 24, 304-311

[120] H. Deng, W. Meredith, C. N. Uguna, C. E. Snape, J. Anal. Appl. Pyrolysis 2015, 113, 340-348

[121] H. J. Shin, C.-J. Kim, S. B. Kim, Biotechnol. Bioprocess Eng. 2009, 14, $349-353$.

[122] G. van Rossum, W. Zhao, M. Castellvi Barnes, J.-P. Lange, S. R. A. Kersten, ChemSusChem 2014, 7, 253-259.

[123] S. Kumar, J.-P. Lange, G. Van Rossum, S. R. A. Kersten, Ind. Eng. Chem Res. 2014, 53, 11668-11676. 
[124] M. S. El-Gayar, C. A. McAuliffe, Energy Sources 1997, 19, 665-676.

[125] E. E. Harris, E. Beglinger, Ind. Eng. Chem. 1946, 38, 890-895.

[126] A. Eyal, R. Jansen, A. Vitner, R. Mali, EP2585606A2, 2013.

[127] N. Yan, C. Zhao, P. J. Dyson, C. Wang, L. Liu, Y. Kou, ChemSusChem 2008, 1, 626-629.

[128] G. Tsilomelekis, T. R. Josephson, V. Nikolakis, S. Caratzoulas, ChemSusChem 2014, 7, 117-126.

[129] X. Qian, D. Liu, Carbohydr. Res. 2014, 388, 50-60.

[130] M. A. Mellmer, C. Sener, J. M. R. Gallo, J. S. Luterbacher, D. M. Alonso, J. A. Dumesic, Angew. Chem. Int. Ed. 2014, 53, 11872-11875; Angew. Chem. 2014, 126, 12066-12069.

[131] V. Vasudevan, S. H. Mushrif, RSC Adv. 2015, 5, 20756-20763.

[132] A. A. Peterson, F. Vogel, R. P. Lachance, M. Fröling, J. Michael, J. Antal, J. W. Tester, Energy Environ. Sci. 2008, 1, 32-65.

[133] C. Reichardt, T. Welton, Solvents and Solvent Effects in Organic Chemistry, Wiley-VCH, Weinheim, 2006

[134] P. Maurel, J. Biol. Chem. 1978, 253, 1677-1683.

[135] R. P. Mariella, R. R. Raube, J. Budde, C. E. Moore, J. Org. Chem. 1954, 19, $678-682$.

[136] J. Catalán, J. Phys. Chem. B 2009, 113, 5951-5960.

[137] J. J. Urban, C. J. Cramer, G. R. Famini, J. Am. Chem. Soc. 1992, 114, $8226-8231$.

[138] A. J. Bridgeman, Chem. Eur. J. 2006, 12, 2094-2102.

[139] D. Hršak, L. Holmegaard, A. S. Poulsen, N. H. List, J. Kongsted, M. P. Denofrio, R. Erra-Balsells, F. M. Cabrerizo, O. Christiansen, P. R. Ogilby, Phys. Chem. Chem. Phys. 2015, 17, 12090-12099.

[140] C. A. Bertolino, A. M. Ferrari, C. Barolo, G. Viscardi, G. Caputo, S. Coluccia, Chem. Phys. 2006, 330, 52-59.

[141] R. I. Cukier, D. G. Nocera, J. Chem. Phys. 1992, 97, 7371-7376.

[142] A. Muñoz-Losa, D. Markovitsi, R. Improta, Chem. Phys. Lett. 2015, 634, 20-24.

[143] H. Heitele, Angew. Chem. Int. Ed. Engl. 1993, 32, 359-377; Angew. Chem. 1993, 105, 378-398.

[144] P. Choto, K. Rasmussen, G. Grampp, Phys. Chem. Chem. Phys. 2015, 17, 3415-3420.

[145] M. Liu, D. H. Waldeck, A. M. Oliver, N. J. Head, M. N. Paddon-Row, J. Am. Chem. Soc. 2004, 126, 10778-10786.

[146] S. Chakrabarti, M. Liu, D. H. Waldeck, A. M. Oliver, M. N. Paddon-Row, J. Phys. Chem. A 2009, 113, 1040-1048.

[147] S. Akimoto, M. Yokono, M. Higuchi, T. Tomo, S. Takaichi, A. Murakami, M. Mimuro, Photochem. Photobiol. Sci. 2008, 7, 1206-1209.

[148] M. Tachiya, Radiat. Phys. Chem. 1996, 47, 43-46.

[149] D. Chakrabarty, P. Hazra, A. Chakraborty, D. Seth, N. Sarkar, Chem. Phys. Lett. 2003, 381, 697-704.

[150] R. Pramanik, S. Sarkar, C. Ghatak, P. Setua, V. G. Rao, N. Sarkar, Chem Phys. Lett. 2010, 490, 154-158.

[151] Protein-Lipid Interactions (New Comprehensive Biochemistry Vol. 25 ), (Ed.: A. Watts), Elsevier, Amsterdam, 1993.

[152] G. Verdasco, M. A. Martín, B. del Castillo, P. López-Alvarado, J. C. Menéndez, Anal. Chim. Acta 1995, 303, 73-78.

[153] T. A. LeGreve, W. H. James, T. S. Zwier, J. Phys. Chem. A 2009, 113, 399 410.

[154] R. M. Adhikari, B. K. Shah, S. S. Palayangoda, D. C. Neckers, Langmuir 2009, 25, 2402-2406.

[155] N. Nedjar-Arroume, D. Guillochon, J. M. Piot, D. Thomas, Biotechnol. Appl. Biochem. 1991, 13, 303-314.

[156] P. L. Overbeeke, J. A. Jongejan, J. J. Heijnen, Biotechnol. Bioeng. 2000, $70,278-290$

[157] M. Wujec, A. Siwek, J. Dzierzawska, M. Rostkowski, R. Kaminski, P. Paneth, J. Phys. Chem. B 2008, 112, 12414-12419.

[158] Y. Levy, J. Jortner, O. M. Becker, Proc. Natl. Acad. Sci. USA 2001, 98, $2188-2193$.

[159] R. J. Nedumpara, K. J. Thomas, V. K. Jayasree, C. P. Girijavallabhan, V. P. N. Nampoori, P. Radhakrishnan, Appl. Opt. 2007, 46, 4786-4792.

[160] U. K. Singh, M. A. Vannice, AlChE J. 1999, 45, 1059-1071.

[161] F. L. Cozens, S. F. Lancelot, N. P. Schepp, J. Org. Chem. 2007, 72, 10022 10028.

[162] K. Suga, K. Ohkubo, S. Fukuzumi, J. Phys. Chem. A 2005, 109, 10168 10175.

[163] S. Gogoi, S. Hazarika, P. G. Rao, N. N. Dutta, Biocatal. Biotransform. 2006, 24, 343-351.
[164] Y. Masuda, J. Phys. Chem. A 2001, 105, 2989-2996.

[165] K.-J. Liu, J. E. Anderson, Macromolecules 1970, 3, 163-164.

[166] J. Najbar, R. C. Dorfman, M. D. Fayer, J. Chem. Phys. 1991, 94, 1081 1092.

[167] A. L. Horvath, J. Phys. Chem. Ref. Data 2006, 35, 77-92.

[168] Y. Lan, M. G. Corradini, X. Liu, T. E. May, F. Borondics, R. G. Weiss, M. A. Rogers, Langmuir 2014, 30, 14128-14142.

[169] J. Lu, J. S. Brown, C. L. Liotta, C. A. Eckert, Chem. Commun. 2001, $665-$ 666.

[170] L. Crowhurst, P. R. Mawdsley, J. M. Perez-Arlandis, P. A. Salter, T. Welton, Phys. Chem. Chem. Phys. 2003, 5, 2790-2794.

[171] C. M. Hansen, Hansen Solubility Parameters: A User's Handbook 2nd ed., CRC Press, Boca Raton, FL, 2007.

[172] Y. Ye, Y. Liu, J. Chang, BioResources 2014, 9, 3417-3427.

[173] A. Brandt, J. Gräsvik, J. P. Hallett, T. Welton, Green Chem. 2013, 15, $550-583$.

[174] J. S. Luterbacher, J.-Y. Parlange, L. P. Walker, Biotechnol. Bioeng. 2013, $110,127-136$

[175] H. E. Grethlein, Nat. Biotechnol. 1985, 3, 155-160.

[176] T. Jeoh, C. I. Ishizawa, M. F. Davis, M. E. Himmel, W. S. Adney, D. K. Johnson, Biotechnol. Bioeng. 2007, 98, 112-122.

[177] B. Yang, C. E. Wyman, Biotechnol. Bioeng. 2004, 86, 88-98.

[178] C. Liu, C. E. Wyman, Ind. Eng. Chem. Res. 2004, 43, 2781-2788.

[179] W. H. Liew, M. H. Hassim, D. K. S. Ng, J. Cleaner Prod. 2014, 71, 11-29.

[180] X. Lu, Y. Zhang, I. Angelidaki, Bioresour. Technol. 2009, 100, 3048-3053.

[181] J. S. Luterbacher, J. M. Moran-Mirabal, E. W. Burkholder, L. P. Walker, Biotechnol. Bioeng. 2015, 112, $32-42$.

[182] S. Haghighi Mood, A. Hossein Golfeshan, M. Tabatabaei, G. Salehi Jouzani, G. H. Najafi, M. Gholami, M. Ardjmand, Renewable Sustainable Energy Rev. 2013, 27, 77-93.

[183] V. Chaturvedi, P. Verma, 3 Biotech, 2013, 3, 415-431.

[184] S. I. Mussatto, M. Fernandes, A. M. F. Milagres, I. C. Roberto, Enzyme Microb. Technol. 2008, 43, 124-129.

[185] K. Öhgren, R. Bura, J. Saddler, G. Zacchi, Bioresour. Technol. 2007, 98 , $2503-2510$.

[186] J. L. Rahikainen, R. Martin-Sampedro, H. Heikkinen, S. Rovio, K. Marjamaa, T. Tamminen, O. J. Rojas, K. Kruus, Bioresour. Technol. 2013, 133 $270-278$.

[187] S. Nakagame, R. P. Chandra, J. N. Saddler in Sustainable Production of Fuels, Chemicals, and Fibers from Forest Biomass (Eds.: J. Y. Zhu, X. Zhang, X. Pan), American Chemical Society, Washington, DC, 2011, pp. $145-167$.

[188] N. Xu, W. Zhang, S. Ren, F. Liu, C. Zhao, H. Liao, Z. Xu, J. Huang, Q. Li, Y. Tu, B. Yu, Y. Wang, J. Jiang, J. Qin, L. Peng, Biotechnol. Biofuels 2012 $5,58$.

[189] Y. Y. Lee, P. Iyer, R. W. Torget in Recent Progress in Bioconversion of Lignocellulose (Ed.: G. T. Tsao), Springer, Berlin, 1999, pp. 93-115.

[190] G. Moxley, A. R. Gaspar, D. Higgins, H. Xu, J. Ind. Microbiol. Biotechnol. 2012, 39, 1289-1299.

[191] J. S. Luterbacher, D. M. Alonso, J. M. Rand, Y. M. Questell-Santiago, J. H. Yeap, B. F. Pfleger, J. A. Dumesic, ChemSusChem 2015, 8, 1317-1322.

[192] R. J. A. Gosselink, W. Teunissen, J. E. G. van Dam, E. de Jong, G. Gellerstedt, E. L. Scott, J. P. M. Sanders, Bioresour. Technol. 2012, 106, 173177

[193] Q. Song, F. Wang, J. Cai, Y. Wang, J. Zhang, W. Yu, J. Xu, Energy Environ. Sci. 2013, 6, 994-1007.

[194] H. Wang, M. Tucker, Y. Ji, J. Appl. Chem. 2013, 2013, e838645.

[195] J. M. W. Chan, S. Bauer, H. Sorek, S. Sreekumar, K. Wang, F. D. Toste, ACS Catal. 2013, 3, 1369-1377.

[196] A. Rahimi, A. Ulbrich, J. J. Coon, S. S. Stahl, Nature 2014, 515, 249-252.

[197] C. Xu, R. A. D. Arancon, J. Labidi, R. Luque, Chem. Soc. Rev. 2014, 43, $7485-7500$.

[198] X. Wang, R. Rinaldi, Angew. Chem. Int. Ed. 2013, 52, 11499-11503; Angew. Chem. 2013, 125, 11713-11717.

[199] Y. Pu, N. Jiang, A. J. Ragauskas, J. Wood Chem. Technol. 2007, 27, 23 33.

[200] D. Fu, S. Farag, J. Chaouki, P. G. Jessop, Bioresour. Technol. 2014, 154, $101-108$.

[201] B. Seger, W. Burchard, Macromol. Symp. 1994, 83, 291-310.

[202] L. Zhang, G. Yang, L. Xiao, J. Membr. Sci. 1995, 103, 65-71.

[203] L. Zhang, G. Yang, W. Fang, J. Membr. Sci. 1991, 56, 207-215. 
[204] Z. Wang, T. Yokoyama, H.-M. Chang, Y. Matsumoto, J. Agric. Food Chem. 2009, 57, 6167-6170.

[205] T. Rosenau, A. Potthast, I. Adorjan, A. Hofinger, H. Sixta, H. Firgo, P. Kosma, Cellulose 2002, 9, 283-291.

[206] O. Biganska, P. Navard, Biomacromolecules 2005, 6, 1948-1953.

[207] H. Dogan, N. D. Hilmioglu, Carbohydr. Polym. 2009, 75, 90-94.

[208] S. Zhu, Y. Wu, Q. Chen, Z. Yu, C. Wang, S. Jin, Y. Ding, G. Wu, Green Chem. 2006, 8, 325-327.

[209] Y. Zhao, X. Liu, J. Wang, S. Zhang, J. Phys. Chem. B 2013, 117, $9042-$ 9049.

[210] R. P. Swatloski, S. K. Spear, J. D. Holbrey, R. D. Rogers, J. Am. Chem. Soc. 2002, 124, 4974-4975.

[211] I. Kilpeläinen, H. Xie, A. King, M. Granstrom, S. Heikkinen, D. S. Argyropoulos, J. Agric. Food Chem. 2007, 55, 9142-9148.

[212] K. C. Badgujar, B. M. Bhanage, Bioresour. Technol. 2015, 178, 2-18.

[213] Y.-H. P. Zhang, S.-Y. Ding, J. R. Mielenz, J.-B. Cui, R. T. Elander, M. Laser M. E. Himmel, J. R. McMillan, L. R. Lynd, Biotechnol. Bioeng. 2007, 97, 214-223.

[214] T. Tsoutsos, D. Bethanis, Energies 2011, 4, 1601-1623.

[215] O. Bobleter, Prog. Polym. Sci. 1994, 19, 797-841.

[216] A. S. Amarasekara, L. D. Williams, C. C. Ebede, Carbohydr. Res. 2008 , 343, $3021-3024$

[217] S. Caratzoulas, D. G. Vlachos, Carbohydr. Res. 2011, 346, 664-672.

[218] X. Qian, J. Phys. Chem. A 2011, 115, 11740-11748.

[219] G. R. Akien, L. Qi, I. T. Horváth, Chem. Commun. 2012, 48, 5850-5852.

[220] Q. P. Peniston, (Food Chemical and Res Lab Inc.) US2750394A, 1956

[221] B. F. M. Kuster, H. J. C. van der Steen, Starch/Staerke 1977, 29, 99-103.

[222] J. A. Dumesic, Y. Román-Leshkov, Top. Catal. 2009, 52, 297-303.

[223] T. M. C. Hoang, E. R. H. van Eck, W. P. Bula, J. G. E. Gardeniers, L. Lefferts, K. Seshan, Green Chem. 2015, 17, 959-972.

[224] J.-P. Lange, E. van der Heide, J. van Buijtenen, R. Price, ChemSusChem 2012, 5, 150-166.

[225] H. D. Phan, T. Yokoyama, Y. Matsumoto, Org. Biomol. Chem. 2012, 10, $7382-7391$

[226] C. P. Kelly, C. J. Cramer, D. G. Truhlar, J. Phys. Chem. B 2007, 111, 408 422.

[227] M. D. Tissandier, K. A. Cowen, W. Y. Feng, E. Gundlach, M. H. Cohen, A. D. Earhart, J. V. Coe, T. R. Tuttle, J. Phys. Chem. A 1998, 102, 77877794.

[228] E. Westphal, J. R. Pliego, Jr., J. Chem. Phys. 2005, 123, 074508

[229] C. Kalidas, G. Hefter, Y. Marcus, Chem. Rev. 2000, 100, 819-852.

[230] J. Galvao, B. Davis, M. Tilley, E. Normando, M. R. Duchen, M. F. Cordeiro, FASEB J. 2014, 28, 1317-1330.

[231] D. J. Nicole, B. Gillet, E. N. Eppiger, J.-J. Delpuech, Tetrahedron Lett. 1982, 23, 1669-1672.

[232] V. Nikolakis, S. H. Mushrif, B. Herbert, K. S. Booksh, D. G. Vlachos, J. Phys. Chem. B 2012, 116, 11274-11283.
[233] A. J. Kunov-Kruse, A. Riisager, S. Saravanamurugan, R. W. Berg, S. B. Kristensen, R. Fehrmann, Green Chem. 2013, 15, 2843-2848.

[234] C. A. Vernon, Proc. R. Soc. London Ser. B 1967, 167, 389-401.

[235] A. J. Kresge, T. S. Straub, J. Am. Chem. Soc. 1983, 105, 3957-3961.

[236] X. Liang, A. Montoya, B. S. Haynes, J. Phys. Chem. B 2011, 115, 10682 10691.

[237] S. J. Dee, A. T. Bell, ChemSusChem 2011, 4, 1166-1173.

[238] L. Lai, Y. Zhang, ChemSusChem 2010, 3, 1257-1259.

[239] J. Han, J. S. Luterbacher, D. M. Alonso, J. A. Dumesic, C. T. Maravelias, Bioresour. Technol. 2015, 182, 258-266.

[240] L. Zhang, H. Yu, P. Wang, Y. Li, Bioresour. Technol. 2014, 151, 355-360.

[241] E. I. Gürbüz, D. M. Alonso, J. Q. Bond, J. A. Dumesic, ChemSusChem 2011, 4, 357-361.

[242] S. Kirchhecker, S. Tröger-Müller, S. Bake, M. Antonietti, A. Taubert, D. Esposito, Green Chem. 2015, 17, 4151-4156.

[243] D. Klein-Marcuschamer, B. A. Simmons, H. W. Blanch, Biofuels Bioprod. Biorefin. 2011, 5, 562-569.

[244] A. George, A. Brandt, K. Tran, S. M. S. N. S. Zahari, D. Klein-Marcuschamer, N. Sun, N. Sathitsuksanoh, J. Shi, V. Stavila, R. Parthasarathi, S. Singh, B. M. Holmes, T. Welton, B. A. Simmons, J. P. Hallet, Green Chem 2015, 17, 1728-1734

[245] F. K. Kazi, J. A. Fortman, R. P. Anex, D. D. Hsu, A. Aden, A. Dutta, G. Kothandaraman, Fuel 2010, 89, S20-S28.

[246] C. Li, Z. Zhang, Z. K. Zhao, Tetrahedron Lett. 2009, 50, 5403-5405.

[247] Y. Zhang, H. Du, X. Qian, E. Y.-X. Chen, Energy Fuels 2010, 24, $2410-$ 2417.

[248] X. Pan, N. Gilkes, J. Saddler, Holzforschung 2006, 60, 398-401.

[249] T. Buntara, I. Melián-Cabrera, Q. Tan, J. L. G. Fierro, M. Neurock, J. G. de Vries, H. J. Heeres, Catal. Today 2013, 210, 106-116.

[250] Donald E. Clark, available from https://www.bnl.gov/esh/cms/pdf/peroxides.pdf.

[251] K. Dossumov, D. Churina, G. Ergazieva, G. Abramova, M. Telbayeva, Chem. Bull. Kazakh Natl. Univ. 2012, $42-49$.

[252] A. G. Gayubo, A. Alonso, B. Valle, A. T. Aguayo, J. Bilbao, Ind. Amp Eng Chem. Res. 2010, 49, 10836-10844.

[253] M. T. Clough, K. Geyer, P. A. Hunt, J. Mertes, T. Welton, Phys. Chem Chem. Phys. 2013, 15, 20480-20495.

[254] K. Korabathina, 2015, available from http://emedicine.medscape.com/ article/1174890-overview.

[255] C. Cursiefen, A. Bergua, Br. J. Ophthalmol. 2002, 86, 1064-1065.

[256] N. Bakhiya, K. E. Appel, Arch. Toxicol. 2010, 84, 563-578.

[257] S. Moro, J. K. Chipman, J.-W. Wegener, C. Hamberger, W. Dekant, A. Mally, Mol. Nutr. Food Res. 2012, 56, 1197-1211.

Received: August 25, 2015

Revised: November 3, 2015

Published online on December 16, 2015 